Subscriber access provided by Uppsala universitetsbibliotek

Kinetics, Catalysis, and Reaction Engineering

\title{
Synthesis and characterization of electrospun nanofibers of Sr- La-Ce oxides as catalysts for the oxidative coupling of methane
}

Brenda M. Sollier, Magali Bonne, Nabyl Khenoussi, Laure Michelin, Eduardo

Ernesto Miró, Leticia Ester Gómez, Alicia V. Boix, and Bénédicte Lebeau

Ind. Eng. Chem. Res., Just Accepted Manuscript • DOI: 10.1021/acs.iecr.0c01154 • Publication Date (Web): 01 Jun 2020

Downloaded from pubs.acs.org on June 4, 2020

\section{Just Accepted}

"Just Accepted" manuscripts have been peer-reviewed and accepted for publication. They are posted online prior to technical editing, formatting for publication and author proofing. The American Chemical Society provides "Just Accepted" as a service to the research community to expedite the dissemination of scientific material as soon as possible after acceptance. "Just Accepted" manuscripts appear in full in PDF format accompanied by an HTML abstract. "Just Accepted" manuscripts have been fully peer reviewed, but should not be considered the official version of record. They are citable by the Digital Object Identifier (DOI®). "Just Accepted" is an optional service offered to authors. Therefore, the "Just Accepted" Web site may not include all articles that will be published in the journal. After a manuscript is technically edited and formatted, it will be removed from the "Just Accepted" Web site and published as an ASAP article. Note that technical editing may introduce minor changes to the manuscript text and/or graphics which could affect content, and all legal disclaimers and ethical guidelines that apply to the journal pertain. ACS cannot be held responsible for errors or consequences arising from the use of information contained in these "Just Accepted" manuscripts. 


\section{Synthesis and characterization of electrospun nanofibers of Sr-La-Ce oxides as catalysts for the oxidative coupling of methane.}

Brenda M. Sollier ${ }^{\mathrm{a}}$, Magali Bonne ${ }^{\mathrm{b}}$, Nabyl Khenoussi ${ }^{\mathrm{c}, \mathrm{d}}$, Laure Michelin ${ }^{\mathrm{b}}$, Eduardo E. Miró $^{\mathrm{a}}$, Leticia E. Gómez ${ }^{\mathrm{a}}$, Alicia V. Boix ${ }^{\mathrm{a}^{*}}$, Bénédicte Lebeau ${ }^{\mathrm{b}}$

a- Instituto de Investigaciones en Catálisis y Petroquímica, INCAPE (FIQ, UNLCONICET), 3000 Santa Fe, Argentina.

b- Université de Haute Alsace (UHA), CNRS, IS2M UMR 7361, F-68100 Mulhouse,

France

c- Université de Haute Alsace (UHA), LPMT, F-68100 Mulhouse, France

d- Université de Strasbourg, 4 rue Blaise Pascal CS 90032 F-67081 Strasbourg France.

*Corresponding autor:

Alicia V. Boix

INCAPE. Santiago del Estero 2829 (3000) Santa Fe Argentina

543424536861

email: aboix@fiq.unl.edu.ar 


\begin{abstract}
Catalytic nanofibers composed of $\mathrm{La}-\mathrm{Ce}$ and $\mathrm{Sr}-\mathrm{La}-\mathrm{Ce}$ oxides were synthetized by electrospinning method with 5 wt.\% of $\mathrm{Sr}$ and different $\mathrm{La} / \mathrm{Ce}$ molar ratios. The materials were obtained by calcining electrospun polymer composite fibers and were studied for the oxidative coupling of methane (OCM). The catalytic performance was compared with analogous Sr-La-Ce powder catalysts.

SEM micrographs of Sr-La-Ce fibers (La/Ce: 0.1, 0.2, 1 and 3) showed nanostructures with homogenous and uniform diameters $(170-200 \mathrm{~nm})$. In addition, the XRD patterns revealed the formation of crystalline solid solutions like $\mathrm{La}_{\mathrm{x}} \mathrm{Ce}_{\mathrm{y}} \mathrm{O}_{\mathrm{z}}$. The strontium enhanced the $\mathrm{CH}_{4}$ conversion and $\mathrm{C}_{2}$ selectivity, since it possibly generated structural defects that promote the formation of superoxide species. The SrLaCe3 nanofibers reached a $\mathrm{CH}_{4}$ conversion of $28.5 \%$ and $\mathrm{C}_{2}$ yield of $21.7 \%$ at $600{ }^{\circ} \mathrm{C}$. The nanofibers randomly packed improved the heat and mass transfer properties due to a high geometric surface ratio with high bed porosity.
\end{abstract}

Keywords: $\mathrm{La}_{\mathrm{x}} \mathrm{Ce}_{\mathrm{y}} \mathrm{O}_{\mathrm{z}}$ solid solution; electrospinning technique; surface characterization; OCM; high $\mathrm{C}_{2}$ yield. 


\section{Introduction}

A large number of fibrous materials have been described in the literature and a significant part of these are in patent documents. In particular, fibrous catalysts offer flexibility and endless forms, which not apply to the usual powdered or granular materials. Comparison of fibers catalysts with powder and monoliths reveals that structured fibrous catalysts are versatile and may find many applications. Cloths made from fibers of easy handling can be packed to fit into almost any geometry. ${ }^{1,2}$

Furthermore, the use of catalytic materials with fibrous structure of micro-nanometric size may present several advantages with respect to powdered ones. They show low resistance to internal diffusion and high surface area to volume ratio because of their very small diameter. These fibrous structures combine less significant temperature gradients and lower pressure drop in a fixed bed reactor than those in powder form due to the high void fractions or bed porosity. ${ }^{3}$

On the other hand, electrospinning is a remarkably simple and powerful technique for generating continuous and thin fibers using a variety of different materials. For application in catalysis, one dimensional polymer fibers that result from electrospinning can be used as a template for synthesis of simple oxide or mixed oxides catalysts. In this process, polymer and inorganic precursors solutions are electrosprayed together to give a composite fiber containing the catalytic precursors which are eliminated with a posterior calcination process. $^{4}$

Recently, nanostructured fiber-based catalysts have ever-increasing attention for the industrial catalysis and environment protection. Fiber-structured catalysts have been developed for a wide range of reactions, including diesel soot combustion ${ }^{5}$, CO 
Oxidation ${ }^{4,6}$, $\mathrm{CO}$ oxidative coupling to $\mathrm{DMO}^{7,8}$, alcohol selective oxidation ${ }^{9,10}$, FischerTropsch synthesis ${ }^{11}$, dry reforming of $\mathrm{CH}_{4}{ }^{12,13}$ methanol to propylene ${ }^{14}$, etc.

In the last decades, the direct and indirect methods to convert methane into more valuable products, including olefins and higher-molecular-weight hydrocarbons, have received great attention. ${ }^{15,16}$ In this vein, oxidative coupling of methane (OCM) is an interesting approach, which holds great prospect in converting methane directly into higher hydrocarbons in the presence of oxygen. ${ }^{17,18}$ The most common product obtained by OCM is ethylene, which is known as a vital chemical platform for synthesis of most petrochemical products. ${ }^{19,20}$

During the $90 \mathrm{~s}$, despite the research efforts devoted to the OCM reaction, no acceptable $\mathrm{C}_{2}$ (ethane and ethylene) yield was accomplished to justify its industrial application. However, some significant conclusions were academically achieved about the reaction mechanism and active catalyst sites. In this way, methane dehydrogenation and methyl radical coupling were considered as the clue reaction steps. ${ }^{21}$ In this way, acceptable reaction performances have been reached with oxides as $\mathrm{MgO}, \mathrm{MnO}_{2}$, and $\mathrm{La}_{2} \mathrm{O}_{3}$. These oxides could be promoted by basic compounds like $\mathrm{Li}, \mathrm{Na}$ and $\mathrm{Sr}$ that can contribute to generate superficial active sites for methane dehydrogenation. ${ }^{22-24}$ Early studies reported that $\mathrm{La}_{2} \mathrm{O}_{3}$ catalysts doping with $\mathrm{Sr}$ showed promising OCM activity because of their high $\mathrm{C}_{2}$ yield and thermal stability. ${ }^{22}$ Moreover, the $\mathrm{CeO}_{2}$ is well known as a redox-active catalyst, which may help to diminish coke formation and thus improve the activity and durability of catalyst. ${ }^{25}$

However, most catalysts for the OCM were studied on its powder form, fixed-bed reactors randomly packed, which is not useful for industrial applications. Therefore, under industrial conditions, high flows should be used at relatively high temperature, structured 
catalysts could be a good option, because they provide lower pressure drop, smaller diffusion resistance and better mass and heat transfer than powder catalysts. ${ }^{26,27}$ Recently, we have reported promising results obtained with $\mathrm{Sr}-\mathrm{La}_{2} \mathrm{O}_{3}$ coated onto ceramic monoliths and foams. Especially, interesting conclusions were obtained with $\mathrm{Sr} / \mathrm{La}_{2} \mathrm{O}_{3}$ catalysts deposited on the walls of cordierite monoliths; an important increase in both, methane conversion and $\mathrm{C}_{2}$ yield, took place. It has been found that monolithic structure provided physical and chemical beneficial effects. That is; the disposition of the catalyst on the straight channel allowed a more homogeneous flow which resulted in a better contact between reactant and catalyst surface and then, in an increase of the overall reaction rate. Moreover the catalytic layer enrichment with $\mathrm{Mg}$ and $\mathrm{Si}$, coming from the cordierite structure, greatly contributed to the improved catalytic behavior. ${ }^{28,29}$ On the other hand, nanofiber-structured catalysts based on $\mathrm{CeO}_{2}-\mathrm{La}_{2} \mathrm{O}_{3}{ }^{30,31}$ and $\mathrm{Sr}-\mathrm{La}_{2} \mathrm{O}_{3}{ }^{32}$ showed relevant catalytic behavior in OCM reaction.

Although the main criteria for industrial application of the OCM demanded that the catalysts were able to reach a $\mathrm{C} 2$ yield higher than $25 \%,{ }^{33}$ some economical estimates demonstrated that the yields about $12 \%-15 \%$ could be sufficient for economically feasible production of ethylene via OCM in the areas where the relative cost of natural gas compared to ethylene is low enough. ${ }^{34}$

In this sense, the production of shale gas has been increasing year by year since new deposits distributed throughout the planet were discovered. Therefore, this fact encourages the production of these higher value products.

Thus, in this work catalysts based on Sr-La-Ce with nanofiber morphology for the oxidative coupling of methane were studied. Therefore, different systems of La-Ce and SrLa-Ce nanofibers were synthesized by the electrospinning method and they were tested in 
the catalytic reaction. The prepared solids were characterized by scanning electron microscopy (SEM) with Energy Dispersive X-Ray Spectroscopy (EDX), X-ray diffraction (XRD) and X-ray photoelectron spectroscopy (XPS). The La-Ce and Sr-La-Ce catalytic fibers were used for the oxidative coupling of methane (OCM) and the performances of the best catalytic fibers were compared to the conventional powder catalysts.

\section{Experimental}

\subsection{Materials and methods}

\subsubsection{Precursor materials}

Cerium nitrate hexahydrate $\left(\mathrm{Ce}\left(\mathrm{NO}_{3}\right)_{3} \cdot 6 \mathrm{H}_{2} \mathrm{O}\right.$, Sigma Aldrich), lanthanum nitrate hexahydrate $\mathrm{La}\left(\mathrm{NO}_{3}\right)_{3} \cdot 6 \mathrm{H}_{2} \mathrm{O}$ (Sigma Aldrich), strontium nitrate $\mathrm{Sr}\left(\mathrm{NO}_{3}\right)_{2}$ (Sigma Aldrich), poly(vinylpyrrolidone) (PVP $\mathrm{M}_{\mathrm{w}}$ 360,000, Sigma Aldrich), ethanol (Sigma Aldrich), citric acid and distilled water were used without further purification.

\subsubsection{Nanofiber catalysts preparation}

Two series of nanostructured catalysts were prepared with different concentrations, one composed of $\mathrm{La}$ and $\mathrm{Ce}$ (labeled LaCex), and the other composed of $\mathrm{La}, \mathrm{Ce}$ and $\mathrm{Sr}$ (labeled SrLaCex) where $\mathrm{x}$ means $\mathrm{La} / \mathrm{Ce}$ molar ratio. The fibers were prepared with an Elmarco's Nanospider (NS 1WS500U series), a wire-electrode needleless electrospinning system. To prepare the electrospinning solution, $1.16 \mathrm{~g}$ of salts were weighted and were dissolved in a mixture of $40 \mathrm{~mL}$ ethanol and $8 \mathrm{~mL}$ water. The amount of each precursor salt was determined in order to obtain the theoretical compositions (molar ratios $\mathrm{La} / \mathrm{Ce}: 0.1$, 
$0.2,1$ and 3) with or without 5 wt.\% of Sr. This mixture was maintained under continuous stirring at room temperature for $15 \mathrm{~min}$. Then, $4 \mathrm{~g}$ PVP was added and the resulting mixture was kept overnight under continuous stirring at room temperature. The prepared solutions were introduced into the machine injector. Firstly, the parameters of the electrospinner were optimized in order to obtain well-formed nanofibers. Pumps were set at different air flows: $30-20,50-40,60-50,70-60 \mathrm{~m}^{3} \mathrm{~h}^{-1}$, and two voltages were also tested at 30 and $40 \mathrm{kV}$. The temperature and humidity were set at room conditions. Electrospun fibers were calcined at $625^{\circ} \mathrm{C}$ in a furnace for 10 hours with a heating ramp of $0.5^{\circ} \mathrm{C} \min ^{-1}$. The calcination temperature was determined by means of TG analysis, proving that at 625 ${ }^{\circ} \mathrm{C}$ all PVP is decomposed. The BET area (specific surface area) of nanofibers was very low, (10-15 $\left.\mathrm{m}^{2} \mathrm{~g}^{-1}\right)$ which indicates that these are dense and do not have internal porosity.

\subsubsection{Powder catalysts preparation}

Some powder catalysts were prepared in order to compare their catalytic performance to nanofibers. La-Ce mixed oxide was synthesized from $\mathrm{Ce}\left(\mathrm{NO}_{3}\right)_{3} \cdot 6 \mathrm{H}_{2} \mathrm{O}$ and $\mathrm{La}\left(\mathrm{NO}_{3}\right)_{3} \cdot 6 \mathrm{H}_{2} \mathrm{O}$ by the citrate method. The proper amounts of precursors were weighted in order to obtain a La:Ce molar ratio of 3. These precursors were dissolved in water and citric acid was added in a molar ratio of $\operatorname{acid} /(\mathrm{Ce}+\mathrm{La})=1$. The final solution was heated up to 80 ${ }^{\circ} \mathrm{C}$ under constant stirring to evaporate superfluous water until a viscous gel was obtained, which was dried at $120^{\circ} \mathrm{C}$ for $24 \mathrm{~h}$ to form a spongy material. Finally, this material was calcined at $625^{\circ} \mathrm{C}$ for $6 \mathrm{~h}$ and it was named as LaCe3-powder.

On the other hand, Sr was added to LaCe3-powder by wet impregnation in the proper amounts to obtain $5 \mathrm{wt} . \%$ of strontium. $\mathrm{Sr}\left(\mathrm{NO}_{3}\right)_{2}$ was dissolved in water and LaCe3-powder 
was added to the solution. The mixture was kept under continuous stirring at $80^{\circ} \mathrm{C}$ for $4 \mathrm{~h}$. Then, it was dried in an oven at $120{ }^{\circ} \mathrm{C}$ overnight and it was calcined at $625{ }^{\circ} \mathrm{C}$ for $6 \mathrm{~h}$. Finally, this sample was called SrLaCe3-powder. The BET areas (specific surface area) were 9.8 and $9.3 \mathrm{~m}^{2} \mathrm{~g}^{-1}$, which suggests that they are non-porous materials.

\subsection{Characterization techniques}

The obtained fibers were analyzed using scanning electron microscopes (JEOL JSMIT100 or Philips XL30). Both were equipped with an EDX analyzer. The samples were first gold-coated using a sputter coater. The mean diameter was measured using image analysis software (Image J) from 100 fibers.

X-Ray diffraction patterns were collected on a PANalytical MPD X'Pert Pro diffractometer operating with $\mathrm{Cu} \mathrm{K}_{\alpha}$ radiation $\left(\mathrm{K}_{\alpha}=0.15418 \mathrm{~nm}\right)$ equipped with an $\mathrm{X}^{\prime}$ Celerator real-time multiple strip detector (active length $=2.12^{\circ} 2 \theta$ ). The powder patterns were collected at $25^{\circ} \mathrm{C}$ in the range $3<2 \theta<70$, step $=0.017^{\circ} 2 \theta$, time/step $=220$ s. The phases identification has been measured with the X'Pert High score software (PANalytical) and the PDF-4+ 2018 database from the International Centre for Diffraction Data (ICDD).

X Ray photoelectron analysis (XPS) was performed in a multi-technique system (SPECS) equipped with a dual Mg/Al X-ray source and a hemispherical PHOIBOS 150 analyzer operating in the fixed analyzer transmission (FAT) mode. The spectra were obtained with a pass energy of $30 \mathrm{eV}$, the $\mathrm{Al} \mathrm{K \alpha}$ X-ray source $(\mathrm{hv}=1486.6 \mathrm{eV})$ was operated at $200 \mathrm{~W}$ and $12 \mathrm{kV}$. The working pressure in the analyzing chamber was less than $2 \cdot 10^{-6} \mathrm{~Pa}$. Casa XPS software was employed for data treatment corresponding to 
regions $\mathrm{O} 1 \mathrm{~s}, \mathrm{C}$ 1s, Sr 3d, La 3d and Ce 3d (as internal reference u"' $916.5 \mathrm{eV}$ ). Peaks were considered as a mixture of Gaussian and Lorentzian functions in a 70/30 ratio.

\subsection{Catalytic tests}

The experiments were conducted in a fixed-bed flow quartz reactor at atmospheric pressure. The reactor design was described in a previous work. ${ }^{29}$ The reactant flow entered the reactor through an inner section of $16 \mathrm{~mm}$ diameter, but below the catalytic bed this inner section was reduced up to $1 / 8$ inch diameter in order to decrease the homogeneous combustion of hydrocarbon products as much as possible.

The system was heated with a furnace to reach the desired temperatures. The exiting gases from the reactor were conducted through a condenser in order to remove $\mathrm{H}_{2} \mathrm{O}$ from the flow. Finally, the exiting flow concentrations were measured using a gas chromatograph (GC-2014 Shimadzu) with thermal conductivity detector (TCD) equipped with two columns, zeolite 5A and Hayesep D. The carbon balance was always higher than $97 \%$. The catalytic tests were repeated several times over the samples, showing quite reproducible results.

The catalytic nanofibers $(250 \mathrm{mg})$ were loosely packed into a $16 \mathrm{~mm}$ (inner diameter) quartz tube between two quartz wool plugs. The bulk density of catalytic bed was approximately $0.06 \mathrm{~g} \mathrm{~cm}^{-3}$. For comparison, powdered catalysts $(500 \mathrm{mg})$ were evaluated; they had a bulk density around $0.5 \mathrm{~g} \mathrm{~cm}^{-3}$.

The reaction mixture consisted of 60 vol. $\% \mathrm{CH}_{4}, 12$ vol.\% $\mathrm{O}_{2}$ and 28 vol.\% He. The gas flow rates were adjusted by means of controllers in order to achieve catalyst- 
weight/total flow ratio $=0.166 \mathrm{mg} \mathrm{cm}^{-3} \mathrm{~h}$. The catalysts were tested in a wide temperature range $\left(250-700{ }^{\circ} \mathrm{C}\right)$. Methane conversion, $\mathrm{C} 2$ selectivity and $\mathrm{C} 2$ yield were calculated as follows:

$$
\begin{gathered}
\text { Methane conversion, } \mathrm{X}_{\mathrm{CH}_{4}}(\%)=\frac{\text { Molar flow of } \mathrm{CH}_{4} \text { reacted }}{\text { Molar flow of } \mathrm{CH}_{4} \text { in feed }} \times 100 \\
C 2 \text { Selectivity, } S_{C 2}(\%)=2 \frac{\text { Molar flow of } C 2}{\text { Molar flow of } \mathrm{CH}_{4} \text { reacted }} \times 100 \\
C 2 \text { Yield, } Y_{C 2}(\%)=\text { Methane conversion } \times C 2 \text { Selectivity } \times \frac{1}{100}
\end{gathered}
$$

Being C2 ethane and/or ethylene.

\section{Results and Discussion}

\subsection{Characterization of catalytic nanofibers}

The theoretical compositions of the catalytic nanofibers La-Ce and Sr-La-Ce obtained by electrospinning are detailed in Table 1 . The $\mathrm{La} / \mathrm{Ce}$ molar ratios were $0.1,0.2,1$ and 3 and the Sr content was $5 \mathrm{wt} . \%$ in all samples.

In order to select the best operating conditions for the formation of nanofibers from the precursor solutions, the parameters in the electrospinning machine were varied. The morphology of the obtained nanofibers was studied by SEM. Micrographs taken from the LaCe3 samples (before calcination) obtained with different electrospinning machine parameters are shown in Figure 1.

Two parameters were varied; air flux and voltage, and seven different samples were obtained. The lowest and highest flux (30 - 20 and $70-60 \mathrm{~m}^{3} \mathrm{~h}^{-1}$, respectively) did not 
show good results (Fig 1 (A), (D) and (G)), no nanofibers were obtained. This behavior was observed with both applied voltages (30 and $40 \mathrm{kV}$ ). It seems that some nanofibers were obtained with $60-50 \mathrm{~m}^{3} \mathrm{~h}^{-1}$ under $40 \mathrm{kV}$, but the sample was heterogeneous and some agglomerations could be seen in Figure 1(F). The sample obtained with this air flux value, but under $30 \mathrm{kV}$ was not composed of nanofibers (Fig. 1(C)). Finally, with the air flux value of $50-40 \mathrm{~m}^{3} \mathrm{~h}^{-1}$ and a voltage of $30 \mathrm{kV}$, homogeneous nanofibers of LaCe3 sample were obtained (Fig. 1(B)). These latter parameters, $50-40 \mathrm{~m}^{3} \mathrm{~h}^{-1}$ and $30 \mathrm{kV}$, were selected to prepare the samples that were studied in this work.

The SEM micrographs of the nanofibers obtained only with the polymer (PVP), the Ce and La salts and PVP (LaCe0.1@PVP) before and after calcination (LaCe0.1) are depicted in Figure 2.

The image of the obtained nanofibers from the PVP polymer is shown in Fig. 2(A). In this case, the fibers diameters are the largest in this studied set with an average diameter of $500 \mathrm{~nm}$, including one that reaches $1.05 \mu \mathrm{m}$. When the salts were added into the electrospinning solution, the average nanofiber diameter decreased, being of around 400 nm (Fig. 2(B)). This decrease could be related to the fact that the addition of salts to the electrospinning solution increases conductivity, improving the spinning procedure. Finally, when the LaCe0.1 nanofibers were calcined, the diameters decreased again, reaching values of around $150 \mathrm{~nm}$ (Fig. 2(C)). This phenomenon is caused by the polymer removal from the nanostructures, and also by the formation of the mixed oxides $\left(\mathrm{La}_{\mathrm{x}} \mathrm{O}_{\mathrm{y}}-\mathrm{Ce}_{\mathrm{z}} \mathrm{O}_{\mathrm{t}}\right)$.

In addition, SEM micrographs of four LaCe compositions (after calcination at $625^{\circ} \mathrm{C}$ ) are depicted in Figure 3. In these samples (A-D) the nanostructures could be seen. The 
samples are homogeneous and uniform. In Figure 3(E) - (G) micrographs at higher magnifications are displayed. In LaCe0.1 SEM micrograph (Fig. 3(E)) it seems that thin nanofibers, of around $140 \mathrm{~nm}$ diameter, are attached each other forming a fiber of larger diameter, between 350 and $450 \mathrm{~nm}$. The same phenomenon is observed in $\mathrm{LaCe} 0.2$ (Fig. 3(F)). LaCe3 sample was somewhat different, the nanofibers are not all of them glued and thin nanofibers of around $200 \mathrm{~nm}$ diameter are observed (Fig. 3(G)). However, there is one big fiber in the middle of the picture for which this phenomenon of nanofibers packing is observed.

Figure 4 shows the SEM micrographs of SrLaCe nanofibers (after calcination at $625^{\circ} \mathrm{C}$ ) from four samples with different compositions. In the first four images (Fig. 4A-D) it could be seen that the nanostructures are homogeneous and uniform. In SrLaCe0.1 micrographs (Fig. 4A and E) shorter nanofibers are observed, indicating that somehow the addition of Sr to the solution contributes to shorten nanostructures. This phenomenon was not observed in the other three samples. In $\mathrm{SrLaCe} 3$ the diameter of the fibers was measured and values of around $171 \mathrm{~nm}$ were obtained (Fig. 4(F)). This diameter was lower than those of LaCe3, suggesting that the addition of $\mathrm{Sr}$ to the electrospinning solution increases its conductivity, improving the experiment conditions and lowering nanofibers diameters. The same average diameter of about $150 \mathrm{~nm}$ was observed for the other three samples (Fig. $4(\mathrm{~F})-(\mathrm{H})$ ).

The atomic concentrations of the different elements determined by EDX analyses in SrLaCe0.1, SrLaCe0.2, SrLaCe1 and SrLaCe3 samples are reported in Table 2. The sample SrLaCe0.1 exhibits a $\mathrm{La}$ and $\mathrm{Ce}$ values of 1.9 and $16.0 \%$, respectively, which results in $\mathrm{La} / \mathrm{Ce}$ ratio of 0.11 , similar to the theoretical one (see Table 1). The oxygen concentration 
(57.2\%) corresponds to the formation of oxides, hydroxides and/or carbonates. The presence of $\mathrm{C}$ could be due to carbonates formation in the samples that will be discussed in the next sections. All samples showed similar Sr concentration (around 4.5-4.7\%), which indicates a homogeneous dispersion of $\mathrm{Sr}$ in nanofibers. Also, the $\mathrm{La} / \mathrm{Ce}$ ratios resulted in 0.26, 1.07 and 3.18 for $\mathrm{SrLaCe} 0.2, \mathrm{SrLaCe} 1$ and $\mathrm{SrLaCe} 3$, respectively, in agreement with the theoretical ones. These results suggest that during synthesis, there is no preferential deposition of any component onto the collector film. Additionally, in the Figure S1 (supporting information) SEM-EDX results and elements spectra measured for SrLaCe3 nanofibers are shown.

On the other hand, SEM image and EDX result for LaCe3 are shown in the Figure S2 (Supporting Information). The formation of very irregularly shaped large particles can be observed in calcined LaCe3 powder.

Figure 5 shows the XRD patterns of four LaCe samples with the positions of the characteristic crystalline $\mathrm{CeO}_{2}$ diffraction peaks (at 28.56, 33.08, 47.48 and $56.34^{\circ} 2 \theta$, full line) and $\mathrm{La}_{2} \mathrm{O}_{3}$ diffraction peaks (at 27.02, 31.31, 44.86 and $53.16^{\circ} 2 \theta$, dot line). ${ }^{35}$ It can be noted that if the pattern of $\mathrm{LaCe} 0.1$ is very close to the pattern of $\mathrm{CeO}_{2}$ the higher the percentages of lanthanum incorporated are, the more shifted to the $\mathrm{La}_{2} \mathrm{O}_{3}$ peak positions the patterns are. These displacements correspond to the formation of solid solutions with $\mathrm{La}_{\mathrm{x}} \mathrm{Ce}_{\mathrm{y}} \mathrm{O}_{\mathrm{z}}$ formula (with $\mathrm{x}$ and $\mathrm{y}$ linked to the peak shifts) and have been confirmed by the identification of the phases found and presented in the Table 1. This identification is in good agreement with the theoretical ratios $\mathrm{La} / \mathrm{Ce}$ and the ratios of the solid solution compositions obtained by XRD, which seems to indicate that the lanthanum is well incorporated in the $\mathrm{CeO}_{2}$ structure. However, the $\mathrm{LaCe} 3$ patterns show the presence of 
additional small quantities of crystalline $\mathrm{CeO}_{2}$. The XRD results are in good agreement with those of Noon and co-workers ${ }^{30}$ for $\mathrm{La}_{2} \mathrm{O}_{3}-\mathrm{CeO}_{2}$ nanofibers. They established that in their samples, solid solutions were formed by reactions between $\mathrm{La}_{2} \mathrm{O}_{3}$ and $\mathrm{CeO}_{2}$, such as the partial reduction of ceria into $\mathrm{Ce}_{7} \mathrm{O}_{12}$ and the incorporation of $\mathrm{La}^{3+}$ ions into the cubic lattice of $\mathrm{CeO}_{2} \cdot{ }^{36,37}$ From XRD patterns, it was estimated the crystallite sizes by means of Scherrer equation for each La-Ce samples. The main diffraction $\mathrm{CeO}_{2}$ signal was used to calculate the size and the obtained values were around 10 and $11 \mathrm{~nm}$.

The SrLaCe XRD patterns are shown in Figure 6. The results are quite similar to those obtained for LaCe samples and give also solid solutions. Nevertheless, in all the patterns, some new XRD peaks appear at 25.34, 25.90, 35.35, 36.78 and $44.11^{\circ} 2 \theta$, which correspond to $\mathrm{SrCO}_{3}$ crystalline phase. ${ }^{38}$ The $\mathrm{SrLaCe} 0.1$ pattern is a little more left shifted than the LaCe0.1 XRD pattern. This pattern identification does not permit to give an exact solid solution composition. As mentioned in the Table 1, several ICDD reference cards could be attributed to this XRD pattern: variable solid compositions ( $\%$ of lanthanum ranges from 0.05 to 0.15 ) could correspond as well an ICDD card (04-021-0597), which contains strontium insertion in the solid solution. For this XRD pattern and the others it is not possible to conclude by XRD if the strontium is well inserted in the solid solutions or just present as crystalline $\mathrm{SrCO}_{3}$. No significant differences are observed in the $\mathrm{SrLaCe} 0.2$ XRD pattern compared to the one of $\mathrm{LaCe} 0.2$, only the presence of peaks characteristic of $\mathrm{SrCO}_{3}$ was observed. For higher lanthanum concentration, it seems that the presence of strontium changes the solid solutions formed. For SrLaCe1, two solid solution compositions can be distinguished and for $\mathrm{SrLaCe} 3$, the pattern shows less incorporation of lanthanum in the solid solution than in the LaCe3 (left shift lower than this of LaCe3). 
On the other hand, XRD patterns of LaCe3-powder and SrLaCe3-powder shown no significant differences compared to $\mathrm{LaCe} 3$ and $\mathrm{SrLaCe} 3$ nanofibers. This fact suggests that the crystalline phases developed during the calcination stage at $625{ }^{\circ} \mathrm{C}$ are similar in powders and nanofibers (See Figure S3 in Supporting Information).

The XPS results from LaCe3 and SrLaCe3 catalysts are shown in Table 3. Both of them were previously used in the OCM reaction. The La $3 \mathrm{~d}$ doublet is well defined showing the satellite structure appearing on the high side of $3 \mathrm{~d}_{5 / 2}$ and $3 \mathrm{~d}_{3 / 2}$ peaks. In LaCe3, the $\mathrm{La} 3 \mathrm{~d}_{5 / 2}$ core level is at $835.6 \mathrm{eV}$ and its corresponding satellite at $+4.0 \mathrm{eV}$ (see Fig. 7(A)). According to literature, both lanthanum species, $\mathrm{La}_{2} \mathrm{O}_{3}$ and $\mathrm{La}(\mathrm{OH})_{3}$, have close binding energies (BEs) positions. ${ }^{39,40}$ Sunding et al. ${ }^{41}$ reported La $3 \mathrm{~d}_{5 / 2}$ values of $835.0 \mathrm{eV}$ for $\mathrm{La}_{2} \mathrm{O}_{3}$ and $835.1 \mathrm{eV}$ for $\mathrm{La}(\mathrm{OH})_{3}$. In our catalyst, $\mathrm{LaCe} 3$, the $\mathrm{La}\left(3 \mathrm{~d}_{5 / 2}-3 \mathrm{~d}_{3 / 2}\right)$ doublet show higher values, suggesting that different chemical environment around La exist (Table 3). This is related to the XRD analysis, which suggested that La-Ce forms mixed oxides. In addition, the incorporation of $\mathrm{Sr}$ to the catalytic system slightly decreases BEs of satellites and main peaks.

The complex Ce $3 \mathrm{~d}$ spectrum of $\mathrm{LaCe} 3$ catalyst was fitted with six component peaks

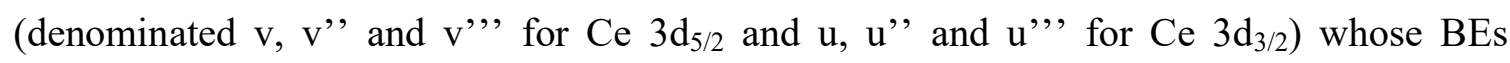
positions were very close to those found for the $\mathrm{CeO}_{2}\left(\mathrm{Ce}^{4+}\right)$. The $\mathrm{Ce} 3 \mathrm{~d}_{5 / 2} \mathrm{BEs}$ in $\mathrm{LaCe} 3$ were $882.9,888.4,898.1 \mathrm{eV}$. According to Paparazzo et al. ${ }^{42}$, these energies are associated to $\mathrm{Ce}^{4+}$ species. This behavior is in agreement with the sample pre-treatments: calcination under air at $625{ }^{\circ} \mathrm{C}$ and the exposure to reaction in oxidizing conditions. The $\mathrm{Sr}$ incorporation to the system does not show significant differences in Ce 3d binding energy positions. 
On the other hand, in $\mathrm{O} 1 \mathrm{~s}$ region three peaks appeared at $529.1,530.6$ and $533.2 \mathrm{eV}$ over LaCe3 catalytic fibers (see Fig. 7(B)). The peak at lower binding energy corresponds to lattice oxygen $\left(\mathrm{O}^{2-}\right)$ which represents $8.9 \%$ of the total amount of oxygen. Whereas the one at $530.6 \mathrm{eV}$ could be attributed to a mixture of different species, including hydroxyl $\left(\mathrm{OH}^{-}\right)$, carbonate $\left(\mathrm{CO}_{3}{ }^{2-}\right)$ and peroxide ion $\left(\mathrm{O}^{-}\right)$, all with similar BEs according to literature. This signal represents $44.8 \%$ of total oxygen. The carbonate and hydroxide species could have been formed on the fiber surface by contact with atmosphere air. The carbonate species were seen also in C 1s region, with a signal around $291 \mathrm{eV}$. The latter oxygen peak, at $533.2 \mathrm{eV}$, is the main signal, with a concentration of $46.3 \%$. In our previous work, this peak was identified as the superoxide species $\left(\mathrm{O}_{2}{ }^{-}\right){ }^{28,29}$ Islam et al. ${ }^{43}$ investigated the formation of peroxide and superoxide species on $\mathrm{Sr}$-La catalysts. It was reported that electron deficient species, such as $\mathrm{O}^{-}$and $\mathrm{O}_{2}^{-}$, on the catalytic surface, are helpful to increase methane molecule activation during OCM reaction. ${ }^{32,44}$ In SrLaCe3 catalytic fibers, the superoxide concentration is significantly higher than in LaCe3. It represents around the $64 \%$ of total oxygen, this suggests that the incorporation of $\mathrm{Sr}$ to the catalytic system increases the amount of active species in SrLaCe3. This latter fact will be discussed in the next section.

In $\mathrm{SrLaCe} 3$ it was also analyzed $\mathrm{Sr} 3 \mathrm{~d}$ region and two components were detected at 134.8 and $136.6 \mathrm{eV}$, the spectrum was introduced in Figure $7(\mathrm{C})$. The signal at lower binding energy corresponds to $\mathrm{SrO}$ and it represents the $63.6 \%$ of $\mathrm{Sr}$, as it is shown in Table 3. The signal that appears at $136.6 \mathrm{eV}$ corresponds to $\mathrm{SrCO}_{3}$ and it is the $36.6 \%$ of total strontium. ${ }^{32,45}$ Nevertheless, these values are at higher BEs than usual (132.1 and $133.9 \mathrm{eV}$ for $\mathrm{SrO}$ and $\mathrm{SrCO}_{3}$ respectively). ${ }^{46}$ J. Kuyyalil et al. ${ }^{47}$, attributed this shift to the 
strontium electrochemical environment. They concluded that this phenomenon could be due to the interaction of $\mathrm{Sr}$ with the oxygen vacancies.

Table 4 shows the surface atomic concentrations calculated from the XPS data of LaCe3 and SrLaCe3. These values show the composition of surface layers with a depth of 20-40 $\AA$, where the La/Ce atomic ratio greater than 3, suggests an enrichment of the surface in lanthanum.

\subsection{Catalytic performance}

Methane conversion versus temperature for $\mathrm{LaCe} 3, \mathrm{LaCe} 1$ and $\mathrm{LaCe} 0.2$ nanofibers is shown in Figure 8 (A). It can be observed that the conversion values increase with the temperature to achieve maximum values of 24.6 and $14.1 \%$ at $600{ }^{\circ} \mathrm{C}$ for $\mathrm{LaCe} 3$ and LaCe 0.2 , respectively, while LaCe1 reaches $20.3 \%$ at $550{ }^{\circ} \mathrm{C}$. Selectivity towards $\mathrm{C}_{2}$ (Fig. 8 (B)) increases with temperature. LaCe3 shows mostly uniform values from 350 to $550{ }^{\circ} \mathrm{C}$, these values raise from 34.4 to $40.3 \%$. At $600{ }^{\circ} \mathrm{C}$, it is observed $62.4 \%$ of $\mathrm{C}_{2}$ selectivity. The LaCe1 nanofibers showed similar behavior, reaching $54.2 \%$ at $600{ }^{\circ} \mathrm{C}$, while $\mathrm{LaCe} 0.2$ selectivity was null at $350-400{ }^{\circ} \mathrm{C}$ and it started to increase at 450 until $600{ }^{\circ} \mathrm{C}$, with a maximum value of $40.1 \%$. In Figure $8(C)$ the $C_{2}$ yield of LaCe nanofibers is shown, as the temperature increases the $\mathrm{C}_{2}$ yield increases, with maximum values at $600{ }^{\circ} \mathrm{C}: 15.4 \%$ for $\mathrm{LaCe} 3,10.3 \%$ for $\mathrm{LaCe} 1$ and $5.6 \%$ for $\mathrm{LaCe} 0.2$. This behavior clearly shows that the lanthanum concentration in the catalyst is key for OCM reaction. The more La concentration in the catalyst is, the better the reaction performance is. To study the nanostructure influence in OCM, it is also included in Figure $8(\mathrm{C}) \mathrm{C}_{2}$ yield of LaCe3powder to compare with the $\mathrm{LaCe} 3$ nanofibers. It could be observed that in the powder 
approximately the same maximum was achieved $(\sim 15 \%)$ but at a higher temperature, 750 ${ }^{\circ} \mathrm{C}$. This is suggesting that the nanostructure is improving the reaction conditions; particularly it is beneficial to lower the working reaction temperature. The differences in surface area and the dispersion of the elements could be also in part responsible for this improvement.

In Figure 9 it is introduced the catalytic performances of SrLaCe nanofibers. Figure 9(A) shows the methane conversion increasing with temperature for the four different catalysts. The best catalytic performance was observed with SrLaCe3 nanofiber, where methane conversion is $10.6 \%$ at $350{ }^{\circ} \mathrm{C}$, and this value augments smoothly to $13.6 \%$ until $500{ }^{\circ} \mathrm{C}$. At $600{ }^{\circ} \mathrm{C}$, it increases notably to $28.5 \%$. To assess the performance at higher temperatures, this catalyst was also tested at $700{ }^{\circ} \mathrm{C}$, and the conversion stayed mostly stable. The same behavior was observed for SrLaCe1, but the conversion was lower, it reached a maximum of $19.1 \%$ at $600{ }^{\circ} \mathrm{C}$. For $\mathrm{SrLaCe} 0.2$ and $\mathrm{SrLaCe} 0.1$ the methane conversion values were lower. In Figure 9 (B) it is shown selectivity towards $\mathrm{C}_{2}$ of SrLaCe nanofibers. SrLaCe0.2 and SrLaCe0.1 selectivities increase with temperature to reach 39.3 and $33.5 \%$ at $600{ }^{\circ} \mathrm{C}$, respectively. The selectivity of $\mathrm{SrLaCe} 3$ varies from 77 to $80 \%$ between 350 and $500{ }^{\circ} \mathrm{C}$. From $500{ }^{\circ} \mathrm{C}$ it decays until $70 \%$ at $700{ }^{\circ} \mathrm{C}$. Although, for $\mathrm{SrLaCe} 1, \mathrm{C}_{2}$ selectivity had an upward trend from $47.7\left(350^{\circ} \mathrm{C}\right)$ to $59.6 \%\left(600{ }^{\circ} \mathrm{C}\right)$. Figure 9(C) introduces the $\mathrm{C}_{2}$ yield of the different $\mathrm{SrLaCe}$ catalysts. The catalysts with low lanthanum concentration, $\mathrm{SrLaCe} 0.1$ and $\mathrm{SrLaCe} 0.2$, showed a $\mathrm{C}_{2}$ yield around $5 \%$. As it was mentioned before, the high concentration of cerium is detrimental for the catalytic activity. Ceria could be lowering the basic character of the catalysts and promoting $\mathrm{C}_{2}$ hydrocarbon further oxidation. When lanthanum and cerium contents are equal, the 
catalytic performance improves, a $\mathrm{C}_{2}$ yield of $11.6 \%$ was achieved at $600{ }^{\circ} \mathrm{C}$. Finally, the best catalytic activity was exhibited by $\mathrm{SrLaCe} 3$. The $\mathrm{C}_{2}$ yield increases with temperature, reaching its maximum of $21.7 \%$ at $600{ }^{\circ} \mathrm{C}$. This follows the same tendency that for the LaCe nanofibers. The catalyst with higher concentration of La shows the best behavior in OCM reaction. Moreover, if the results of $\mathrm{LaCe} 3$ and $\mathrm{SrLaCe} 3$ are compared, it could be clearly seen that the addition of $\mathrm{Sr}$ to the nanofiber improves the catalytic performance.

In addition, these catalytic results were better than those reported in our previous works, where monolithic $\mathrm{Sr} / \mathrm{La}_{2} \mathrm{O}_{3}$ catalysts reached a $\mathrm{C} 2$ yield of $18 \%$ at $800{ }^{\circ} \mathrm{C}$ on $\mathrm{OCM}$ reaction. The composition of the fibers arranged in a controlled structure are able to achieve higher C2 yields at lower temperatures. Table TS1 in Supporting information section shows a comparison of catalytic activity of $\mathrm{La}_{2} \mathrm{O}_{3}$-based catalysts under the form of different structures; powder, monoliths and nanofibers. It could be observed that the yield to $\mathrm{C} 2$ products rises when the catalysts was deposited on a monolithic structure with respect to a $\mathrm{Sr} / \mathrm{Al}_{2} \mathrm{O}_{3}$ powder. On the other hand, when a low percentage of $\mathrm{CeO}_{2}$ (atomic ratio $\mathrm{La} / \mathrm{Ce}=3$ ) was added to $\mathrm{Sr} / \mathrm{Al}_{2} \mathrm{O}_{3}$ powder it reached higher $\mathrm{C} 2$ yield and a lower temperature $\left(750^{\circ} \mathrm{C}\right)$ than the others $\left(800^{\circ} \mathrm{C}\right)$. Even more, when the Sr-La-Ce catalysts were made by electrospinning as nanofiber structures, the highest $\mathrm{C} 2$ yield was obtained $(21.7 \%)$ and at temperature considerably lower $\left(600^{\circ} \mathrm{C}\right)$.

According to XPS results, the catalytic surface of $\mathrm{SrLaCe} 3$ had higher concentration of superoxides species $(\sim 64 \%)$ than LaCe3 $(\sim 46 \%)$. As it was mentioned before, it is believed that oxygen species that have an electron deficiency, as $\mathrm{O}_{2}^{-}$and $\mathrm{O}^{-}$, are the active sites in OCM reaction. ${ }^{43}$ Moreover, the Sr incorporation into the catalyst was highly studied in this process. ${ }^{48-50}$ It is known that the insertion of strontium into the lattice of the host 
oxides affects its defect structure, and causes the formation of oxygen-anion vacancies. ${ }^{51,52}$ These lattice defects are supposed to play an important role in the OCM and they are related to the superoxide and peroxide species.

Some other tests were performed over $\mathrm{SrLaCe} 3$ in order to understand the behavior observed between 350 and $500{ }^{\circ} \mathrm{C}$ where $\mathrm{C}_{2}$ yield raised smoothly and then jumped surprisingly at $550{ }^{\circ} \mathrm{C}$. The run was repeated and the catalytic measurements were performed while increasing temperature and after that, decreasing it. In the second case, only slightly higher $\mathrm{C}_{2}$ yield values were obtained between 600 and $450{ }^{\circ} \mathrm{C}$. The described results can be interpreted on the light of the mechanism proposed by Karakaya et al. ${ }^{25}$ In their study of OCM reaction mechanism over $\mathrm{La}_{2} \mathrm{O}_{3} / \mathrm{CeO}_{2}$ nanofibers, they suggest that both gas-phase and surface reactions play significant roles for $\mathrm{CH}_{4}$ activation, as well as $\mathrm{C}_{2}$ and $\mathrm{CO}_{\mathrm{x}}$ formation. Despite differences in the active catalytic sites for particular catalysts, it is generally known that the methane activation proceeds via the $\mathrm{CH}_{3} \bullet$ radical. The initiating $\mathrm{CH}_{3}{ }^{\bullet}$ formation reactions control the overall reaction rate. They propose two contributions to the heterogeneous pathway. One is the reaction of methane with surface-adsorbed oxygen. ${ }^{53}$ This step is promoted by the oxygen vacancies that are produced because of the introduction of some elements into the catalysts oxygen lattice, creating defects. That could be the case of $\mathrm{Sr}$, as it was discussed in the previous paragraphs. This phenomenon may be the one that is prevailing at low temperature (between $400-500{ }^{\circ} \mathrm{C}$ ). The second heterogeneous contribution for the methane activation can also be accomplished by reacting $\mathrm{CH}_{4}$ with $\mathrm{OH}^{\bullet}$ radicals due to the $\mathrm{O}-\mathrm{H}$ bonds in $\mathrm{H}_{2} \mathrm{O}\left(497 \mathrm{~kJ} \mathrm{~mol}^{-1}\right)$ are stronger than the $\mathrm{C}$ $\mathrm{H}$ bond in $\mathrm{CH}_{4}\left(439 \mathrm{~kJ} \mathrm{~mol}^{-1}\right){ }^{54,55}$ These radicals can be found onto the catalytic surface, and they prevail at higher temperatures. Therefore, this could be the cause of the strong 
increase in $\mathrm{C}_{2}$ yield observed from 550 to $600{ }^{\circ} \mathrm{C}$. There exist some other reactions in the gas-phase chemistry that contributes to $\mathrm{CH}_{3}{ }^{\bullet}$ formation via both, oxidative and nonoxidative reactions which are generally known from combustion research. ${ }^{55,56}$ However, this latter gas-phase chemistry route has less effect in OCM reaction than the heterogeneous pathway. The catalytic test shown in Figure 9, in which we study the reaction behavior increasing and decreasing temperature, indicated no deactivation of the catalyst in 40 hours of time-on-stream.

In addition, SrLaCe3-powder was prepared in order to compare with the nanostructured fibers. It is clearly shown in Figure $9(\mathrm{C})$ that the powder exhibits worse $\mathrm{C}_{2}$ yields than the nanofibers. Moreover, the maximum yield of $19.5 \%$ was reached at $750{ }^{\circ} \mathrm{C}$. Once more, the nanostructure is beneficial and it highly improves $\mathrm{C}_{2}$ yield in OCM reaction. As said before, no only the morphology of the fibers is important in determining in improving $\mathrm{C}_{2}$, the influence of the surface properties and the dispersion of the elements should not ruled out. Finally, it is demonstrated that the nanofiber structure allows the catalytic system to reach the maximum yields at lower temperatures, $150{ }^{\circ} \mathrm{C}$ less. This phenomenon was already seen by other authors, and it could be ascribed to higher mass transfer properties of nanofiber catalysts as compared with the powder ones. ${ }^{57}$. Another important feature of nanofibers is the high aspect ratio, which gives rise to randomly packed beds with a much higher porosity. ${ }^{4}$ The combination of a relatively high geometric surface area with high bed porosity would favour the methane dehydrogenation step, which is the rate-limiting one, and the release of methyl radicals to the gas phase, where they can be coupled to form ethane and ethylene. This could be a suitable explanation for the better performance of the nanofibers as compared to their powder form. 
Another important factor that should be considered is the temperature profile inside the reactor. Due to OCM is a strongly exothermic reaction, the possible formation of hot spots with temperatures higher than those measured must be considered. However, we concluded that due to the low reactant flow and concentrations used in the experiments the heat flux calculated from the reaction enthalpy and the observed methane conversion is low $(2.12 \mathrm{~W})$. Therefore, the formation of important hot spots inside the reactor, not detected by the thermocouple, it is not expected. However, this is an important point to be taken into account, and requires further analysis, for example using a theoretical model to predict radial and axial temperature profiles. A thorough study about this point has been recently reported. ${ }^{58}$

The $\mathrm{C}_{2}$ yield of $\mathrm{SrLaCe} 3$ is between the highest values reported in the literature at this temperature. It is believed that the tri-component catalysts show the best performances in OCM. ${ }^{24}$ Notably, Othman et al. reported that an OCM reaction conducted in a novel microreactor composed of a hollow fiber membrane (made of $\mathrm{La}_{0.6} \mathrm{Sr}_{0.4} \mathrm{Co}_{0.2} \mathrm{Fe}_{0.8} \mathrm{O}_{3-\delta}$ (LSCF)) led to an excellent $\mathrm{C}_{2}$ yield of $39 \%$ (highest reported so far in literature) at an approximate methane conversion of $50 \%{ }^{59}$ However, these results were obtained at $900^{\circ} \mathrm{C}$.

\section{Conclusions}

In summary, the addition of 5 wt. $\%$ of $\mathrm{Sr}$ to $\mathrm{La}_{2} \mathrm{O}_{3}-\mathrm{CeO}_{2}$ nanofibers enhances the $\mathrm{CH}_{4}$ conversion and $\mathrm{C}_{2}$ selectivity, specially for $\mathrm{SrLaCe} 3$ and $\mathrm{SrLaCe} 1$. The catalyst with higher concentration of lanthanum shows the best behavior in OCM reaction. The addition of $\mathrm{Sr}$ promotes the formation of electron deficient oxygen species (as $\mathrm{O}^{2-}$ and $\mathrm{O}^{-}$) on the catalytic surface which constitute active sites in the oxidative coupling of methane reaction. 
The synergistic effects from combinations of each component in Sr-La-Ce nanofibers brought about an improved catalytic behavior for the OCM reaction carried out at lower temperature, which cannot be achieved over the conventional SrLaCe powder catalysts.

In the LaCe and SrLaCe nanofibers as well as in $\mathrm{LaCe} 3$ and SrLaCe3 powders, the formation of crystalline solid solutions with $\mathrm{La}_{\mathrm{x}} \mathrm{Ce}_{\mathrm{y}} \mathrm{O}_{\mathrm{z}}$ formula were detected by XRD, in agreement with theoretical ratios $\mathrm{La} / \mathrm{Ce}$, where the lanthanum was well incorporated in the $\mathrm{CeO}_{2}$ structure.

For $\mathrm{SrLaCe} 3$ nanofibers $\mathrm{CH}_{4}$ conversion and $\mathrm{C}_{2}$ yield were up to $28.5 \%$ and $21.7 \%$ at $600{ }^{\circ} \mathrm{C}$, respectively; while SrLaCe3-powder achieves $\mathrm{C}_{2}$ yield of $19 \%$ at $750{ }^{\circ} \mathrm{C}$. This behavior was ascribed to higher heat and mass transfer properties of catalytic nanofibers as compared with powder one. In addition, the combination of a relatively high geometric surface area with high bed porosity of nanofibers improves the catalytic performance on OCM reaction.

\section{Conflict of interest}

There are not conflicts to declare.

\section{Acknowledgement}

The authors wish to acknowledge the financial support received from UNL, ANPCyT and CONICET. SEM, XRD and TGA measurements/analyses were performed on the technical platforms of IS2M (ISO9001). Thanks are given to Maedeh Vafaee for her help during electrospinning experiments. We also want to thanks to the governments of France and Argentina for granted Brenda with the Saint-Exupery scholarship. 


\section{References}

(1) Thenmozhi, S.; Dharmaraj, N.; Kadirvelu, K.; Kim, H. Y. Electrospun nanofibers: New generation materials for advanced applications. Mater. Sci. Eng. B Solid-State Mater. Adv. Technol. 2017, 217, 36-48.

(2) Matatov-Meytal, Y.; Sheintuch, M. Catalytic fibers and cloths. Appl. Catal. A Gen. 2002, 231, 1-16.

(3) Ternero-Hidalgo, J. J.; Torres-Liñán, J.; Guerrero-Pérez, M. O.; Rodríguez-Mirasol, J.; Cordero, T. Electrospun Vanadium Oxide based submicron diameter fiber catalysts. Part I: Preparation procedure and propane ODH application. Catal. Today 2019, 325, 131-143.

(4) Moreno, I.; Navascues, N.; Irusta, S.; Santamaria, J. Electrospun $\mathrm{Au} / \mathrm{CeO}_{2}$ Nanofibers: A highly accessible low-pressure drop catalyst for preferential CO oxidation. J. Catal. 2015, 329, 479-489.

(5) Stegmayer, M. Á.; Milt, V. G.; Navascues, N.; Gamez, E.; Irusta, S.; Miró, E. E. Cobalt deposited on micro and nanometric structures of ceria and irconia applied in diesel soot combustion. Mol. Catal. 2020, 481, 100636.

(6) Tao, L.; Zhao, G.; Chen, P.; Zhang, Z.; Liu, Y.; Lu, Y. Thin-felt mcrofibrousstructured $\mathrm{Au}-\alpha-\mathrm{Fe}_{2} \mathrm{O}_{3} /$ ns- $\gamma-\mathrm{Al}_{2} \mathrm{O}_{3} / \mathrm{Al}$-fiber catalyst for high-throughput $\mathrm{CO}$ oxidation. Appl. Catal. A Gen. 2018, 556, 180-190.

(7) Wang, C.; Han, L.; Chen, P.; Zhao, G.; Liu, Y.; Lu, Y. High-performance, low Pd- 
loading microfibrous-structured Al-Fiber@ns-A1OOH@Pd catalyst for CO coupling to dimethyl oxalate. J. Catal. 2016, 337, 145-156.

(8) Wang, C.; Ding, J.; Zhao, G.; Deng, T.; Liu, Y.; Lu, Y. microfibrous-structured $\mathrm{Pd} / \mathrm{AlOOH} / \mathrm{Al}-\mathrm{Fiber}$ for $\mathrm{CO}$ coupling to dimethyl oxalate: effect of morphology of $\mathrm{AlOOH}$ nanosheet endogenously grown on Al-fiber. ACS Appl. Mater. Interfaces 2017, 9, 9795-9804.

(9) Zhao, G.; Deng, M.; Jiang, Y.; Hu, H.; Huang, J.; Lu, Y. Microstructured Au/Nifiber catalyst: galvanic reaction preparation and catalytic performance for lowtemperature gas-phase alcohol oxidation. J. Catal. 2013, 301, 46-53.

(10) Zhang, Q.; Li, Y.; Zhang, L.; Chen, L.; Liu, Y.; Lu, Y. Thin-Sheet MicrofibrousStructured Nanoporous Gold/Al Fiber Catalysts for Oxidative Coupling of Methanol to Methyl Formate. J. Catal. 2014, 317, 54-61.

(11) Han, L.; Wang, C.; Ding, J.; Zhao, G.; Liu, Y.; Lu, Y. Microfibrous-structured Alfiber@ns- $\mathrm{Al}_{2} \mathrm{O}_{3}$ core-shell composite functionalized by Fe-Mn-K via surface impregnation combustion: as-Burnt catalysts for synthesis of light olefins from syngas. $R S C A d v$. 2016, 6, 9743-9752.

(12) Chai, R.; Fan, S.; Zhang, Z.; Chen, P.; Zhao, G.; Liu, Y.; Lu, Y. Free-standing NiO$\mathrm{MgO}-\mathrm{Al}_{2} \mathrm{O}_{3}$ nanosheets derived from layered double hydroxides grown onto FeCrAl-Fiber as structured catalysts for dry reforming of methane. ACS Sustain. Chem. Eng. 2017, 5, 4517-4522.

(13) Chen, W.; Sheng, W.; Cao, F.; Lu, Y. Microfibrous entrapment of $\mathrm{Ni} / \mathrm{Al}_{2} \mathrm{O}_{3}$ for dry 
reforming of methane: Heat/mass transfer enhancement towards carbon resistance and conversion promotion. Int. J. Hydrogen Energy 2012, 37, 18021-18030.

(14) Wang, X.; Wen, M.; Wang, C.; Ding, J.; Sun, Y.; Liu, Y.; Lu, Y. Microstructured fiber@HZSM-5 core-shell catalysts with dramatic selectivity and stability improvement for the methanol-to-propylene process. Chem. Commun. 2014, 50, $6343-6345$.

(15) Lunsford, J. H. Catalytic conversion of methane to more useful chemicals and fuels: A challenge for the 21st Century. Catal. Today 2000, 63, 165-174.

(16) Schwach, P.; Pan, X.; Bao, X. Direct Conversion of methane to value-added chemicals over heterogeneous catalysts: challenges and prospects. Chem. Rev. 2017, $117,8497-8520$.

(17) Kondratenko, E. V.; Peppel, T.; Seeburg, D.; Kondratenko, V. A.; Kalevaru, N.; Martin, A.; Wohlrab, S. Methane conversion into different hydrocarbons or oxygenates: Current status and future perspectives in catalyst development and reactor operation. Catal. Sci. Technol. 2017, 7, 366-381.

(18) Olivos-Suarez, A. I.; Szécsényi, À.; Hensen, E. J. M.; Ruiz-Martinez, J.; Pidko, E. A.; Gascon, J. Strategies for the direct catalytic valorization of methane using heterogeneous catalysis: challenges and opportunities. ACS Catal. 2016, 6, 29652981.

(19) Galadima, A.; Muraza, O., Revisiting the oxidative coupling of methane to ethylene in the golden period of shale Gas : a review. J. Ind. Eng. Chem. 2016, 37, 1-13. 
(20) Gambo, Y.; Jalil, A. A.; Triwahyono, S.; Abdulrasheed, A. A. Recent advances and future prospect in catalysts for oxidative coupling of methane to ethylene : A Review. J. Ind. Eng. Chem. 2018, 59, 218-229.

(21) Lane, G. S.; Miró, E. E.; Wolf, E. E. Methane oxidative coupling: II. A study of Lithium-Titania-catalyzed reactions of methane. J. Catal. 1989, 119, 161-178.

(22) Deboy, J. M.; Hicks, R. F. Kinetics of the Oxidative Coupling of Methane over 1 $\mathrm{Wt} \% \mathrm{Sr} / \mathrm{La}_{2} \mathrm{O}_{3}$. J. Catal. 1988, 113, 517-524.

(23) Habibpoor, H.; Taghizadeh, M.; Raouf, F. Oxidative coupling of methane over $\mathrm{Li} / \mathrm{MgO}$ catalysts prepared by sol-gel and impregnation methods. Inorg. Nano-Metal Chem. 2017, 47, 1449-1456.

(24) Kondratenko, E. V.; Schlüter, M.; Baerns, M.; Linke, D.; Holena, M. Developing catalytic materials for the oxidative coupling of methane through statistical analysis of literature data. Catal. Sci. Technol. 2015, 5, 1668-1677.

(25) Karakaya, C.; Zhu, H.; Zohour, B.; Senkan, S.; Kee, R. J. Detailed reaction mechanisms for the oxidative coupling of methane over $\mathrm{La}_{2} \mathrm{O}_{3} / \mathrm{CeO}_{2}$ nanofiber fabric catalysts. Chem CatChem 2017, 9, 4538-4551.

(26) Groppi, G.; Tronconi, E. Design of novel monolith catalyst supports for gas/solid reactions with heat exchange. Chem. Eng. Sci. 2000, 55, 2161-2171.

(27) Cybulski, A.; Moulin, J. Monoliths in Heterogeneous Catalysis. Catal. Rev. 1994, $36,179-270$. 
(28) Sollier, B. M.; Gómez, L. E.; Boix, A. V.; Miró, E. E. Oxidative coupling of methane on $\mathrm{Sr} / \mathrm{La}_{2} \mathrm{O}_{3}$ catalysts: Improving the catalytic performance using cordierite monoliths and ceramic foams as structured substrates. Appl. Catal. A Gen. 2017, $532,65-76$.

(29) Sollier, B. M.; Gómez, L. E.; Boix, A. V.; Miró, E. E. Oxidative coupling of methane on cordierite monoliths coated with $\mathrm{Sr} / \mathrm{La}_{2} \mathrm{O}_{3}$ catalysts. Influence of honeycomb structure and catalyst-cordierite chemical interactions on the catalytic behavior. Appl. Catal. A Gen. 2018, 550, 113-121.

(30) Noon, D.; Seubsai, A.; Senkan, S. Oxidative coupling of methane by nanofiber catalysts. Chem CatChem 2013, 5, 146-149.

(31) Noon, D.; Zohour, B.; Bae, A.; Seubsai, A.; Senkan, S. Effects of Ir-doping on the transition from oxidative coupling to partial oxidation of methane in $\mathrm{La}_{2} \mathrm{O}_{3}-\mathrm{CeO}_{2}$ nanofiber catalysts: Spatial concentration and temperature profiles. $R S C A d v . \mathbf{2 0 1 7}$, 7, 26783-26789.

(32) Song, J.; Sun, Y.; Ba, R.; Huang, S.; Zhao, Y.; Zhang, J.; Sun, Y.; Zhu, Y. Monodisperse $\mathrm{Sr}-\mathrm{La}_{2} \mathrm{O}_{3}$ hybrid nanofibers for oxidative coupling of methane to synthesize C2 hydrocarbons. Nanoscale 2015, 7, 2260-2264.

(33) Xu, Y.; Bao, X.; Lin, L. Direct conversion of methane under nonoxidative conditions. J. Catal. 2003, 216, 386-395.

(34) Sinev, M. Y.; Fattakhova, Z. T.; Lomonosov, V. I.; Gordienko, Y. A. Kinetics of oxidative coupling of methane: bridging the gap between comprehension and 
description. J. Nat. Gas Chem. 2009, 18, 273-287.

(35) Lacoste, A. M.; Tiscornia, I. S.; Boix, A. V. CO preferential oxidation on cordierite monoliths coated with $\mathrm{CuO}-\mathrm{CeO}_{2} / \mathrm{SBA}-15$ catalysts. Further insights into the physico-chemical aspects of the catalytic behavior. Int. J. Hydrogen Energy 2018, $43,14238-14251$.

(36) Dedov, A. G.; Loktev, A. S.; Moiseev, I. I.; Aboukais, A.; Lamonier, J. F.; Filimonov, I. N. Oxidative coupling of methane catalyzed by rare earth oxides: Unexpected synergistic effect of the oxide mixtures. Appl. Catal. A Gen. 2003, 245, $209-220$.

(37) Cao, X.; Vassen, R.; Fischer, W.; Tietz, F.; Jungen, W.; Stöver, D. LanthanumCerium Oxide as a thermal barrier-coating material for high-temperature applications. Adv. Mater. 2003, 15, 1438-1442.

(38) Iida, H.; Fujiyama, A.; Igarashi, A.; Okumura, K. Steam reforming of toluene over $\mathrm{Ru} / \mathrm{SrCO}_{3}-\mathrm{Al}_{2} \mathrm{O}_{3}$ catalysts. Fuel Process. Technol. 2017, 168, 50-57.

(39) Faroldi, B. M.; Lombardo, E. A.; Cornaglia, L. M. Surface properties and catalytic behavior of $\mathrm{Ru}$ supported on composite $\mathrm{La}_{2} \mathrm{O}_{3}-\mathrm{SiO}_{2}$ oxides. Appl. Catal. A Gen. 2009, 369, 15-26.

(40) Gallaher, G.; Goodwin, J.; Huang, C.-S.; Houalla, M. XPS and reaction investigation of alkali promotion of $\mathrm{Rh} / \mathrm{La}_{2} \mathrm{O}_{3} . J$. Catal. 1993, 140, 453-463.

(41) Sunding, M. F.; Hadidi, K.; Diplas, S.; Løvvik, O. M.; Norby, T. E.; Gunnæs, A. E. XPS characterisation of in situ treated lanthanum oxide and hydroxide using tailored 
charge referencing and peak fitting procedures. J. Electron Spectros. Relat. Phenomena 2011, 184, 399-409.

(42) Paparazzo, E. XPS Studies of damage induced by X-Ray irradiation on $\mathrm{CeO}_{2}$ surfaces. Surf. Sci. 1990, 234, L253-L258.

(43) Islam, M. S.; Ilett, D. J.; Parker, S. C. Surface structures and oxygen hole formation on the $\mathrm{La}_{2} \mathrm{O}_{3}$ catalyst. A computer simulation study. J. Phys. Chem. 1994, 98, 96379641.

(44) Ferreira, V. J.; Tavares, P.; Figueiredo, J. L.; Faria, J. L. Ce-doped $\mathrm{La}_{2} \mathrm{O}_{3}$ based catalyst for the oxidative coupling of methane. Catal. Commun. 2013, 42, 50-53.

(45) Bukhtiyarova, M. V.; Ivanova, A. S.; Plyasova, L. M.; Litvak, G. S.; Rogov, V. A.; Kaichev, V. V.; Slavinskaya, E. M.; Kuznetsov, P. A.; Polukhina, I. A. Selective catalytic reduction of nitrogen oxide by ammonia on $\mathrm{Mn}(\mathrm{Fe})$-substituted $\mathrm{Sr}(\mathrm{La})$ aluminates. Appl. Catal. A Gen. 2009, 357, 193-205.

(46) Shen, V. K.; Siderius, D. W.; Krekelberg, W. P.; Hatch, H. W. NIST Standard Reference Simulation Website, NIST Standard Reference Database Nummber 173. National Institute of Standars and Technology http://doi.org/10.18434/T4M88Q.

(47) Kuyyalil, J.; Newby, D.; Laverock, J.; Yu, Y.; Cetin, D.; Basu, S. N.; Ludwig, K.; Smith, K. E. Vacancy assisted SrO formation on $\mathrm{La}_{0.8} \mathrm{Sr}_{0.2} \mathrm{Co}_{0.2} \mathrm{Fe}_{0.8} \mathrm{O}_{3-\delta}$ surfaces - A synchrotron photoemission study. Surf. Sci. 2015, 642, 33-38.

(48) Cong, L.; Zhao, Y.; Li, S.; Sun, Y. Sr-doping effects on $\mathrm{La}_{2} \mathrm{O}_{3}$ catalyst for oxidative coupling of methane. Chinese J. Catal. 2017, 38, 899-907. 
(49) Choudhary, V. R.; Mulla, S. A. R.; Rane, V. H. Oxidative coupling of methane and oxidative dehydrogenation of ethane over strontium-promoted rare earth oxide catalysts. J. Chem. Technol. Biotechnol. 1998, 71, 167-172.

(50) González-Cortés, S. L.; Orozco, J.; Fontal, B. Oxidative transformation of methane on $1.5 \mathrm{Mol} \% \mathrm{Sr}^{2+} / \mathrm{La}_{2} \mathrm{O}_{3}$-supported nickel catalysts. Appl. Catal. A Gen. 2001, 213, $259-271$.

(51) Mestl, G.; Knozinger, H.; Lunsford, J. H. High temperature in situ Raman spectroscopy of working oxidative coupling catalysts. Ber. Bunsenges Phys. Chem. 1993, 97, 319-321.

(52) Stefov, V.; Abdija, Z.; Najdoski, M.; Koleva, V.; Petruševski, V. M.; Runčevski, T.; Dinnebier, R. E.; Šoptrajanov, B. Infrared and Raman spectra of magnesium ammonium phosphate hexahydrate (Struvite) and its isomorphous analogues. IX: Spectra of protiated and partially deuterated cubic magnesium caesium phosphate hexahydrate. Vib. Spectrosc. 2013, 68, 122-128.

(53) Thybaut, J. W.; Sun, J.; Olivier, L.; Van Veen, A. C.; Mirodatos, C.; Marin, G. B. Catalyst design based on microkinetic models: Oxidative coupling of methane. Catal. Today 2011, 159, 29-36.

(54) Takanabe, K.; Iglesia, E. Rate and selectivity enhancements mediated by $\mathrm{OH}$ radicals in the oxidative coupling of methane catalyzed by $\mathrm{Mn} / \mathrm{Na}_{2} \mathrm{WO}_{4} / \mathrm{SiO}_{2}$. Angew. Chemie - Int. Ed. 2008, 47, 7689-7693.

(55) Reyes, S.; Iglesia, E.; Kelkar, C. P. Kinetic-transport models of bimodal reaction 
sequences- I. Homogeneous and heterogeneous pathways in oxidative coupling of methane. Chem. Eng. Sci. 1993, 48, 2643-2661.

(56) Chen, Q.; Couwenberg, P. M.; Marin, G. B. Effect of pressure on the oxidative coupling of methane in the absence of catalyst. AIChE J. 1994, 40, 521-535.

(57) Farsi, A.; Mansouri, S. S. Influence of nanocatalyst on oxidative coupling, steam and dry reforming of methane: A short review. Arab. J. Chem. 2016, 9, S28-S34.

(58) Liu, Z.; Ho Li, J. P.; Vovk, E.; Zhu, Y.; Li, S.; Wang, S.; Van Bavel, A. P.; Yang, Y. Online kinetics study of oxidative coupling of methane over $\mathrm{La}_{2} \mathrm{O}_{3}$ for methane activation: What Is behind the distinguished light-off temperatures? ACS Catal. 2018, 8 (12), 11761-11772.

(59) Othman, N. H.; Wu, Z.; Li, K. An oxygen permeable membrane microreactor with an in-situ deposited $\mathrm{Bi}_{1.5} \mathrm{Y}_{0.3} \mathrm{Sm}_{0.2} \mathrm{O}_{3-\delta}$ catalyst for oxidative coupling of Methane. $J$. Memb. Sci. 2015, 488, 182-193. 


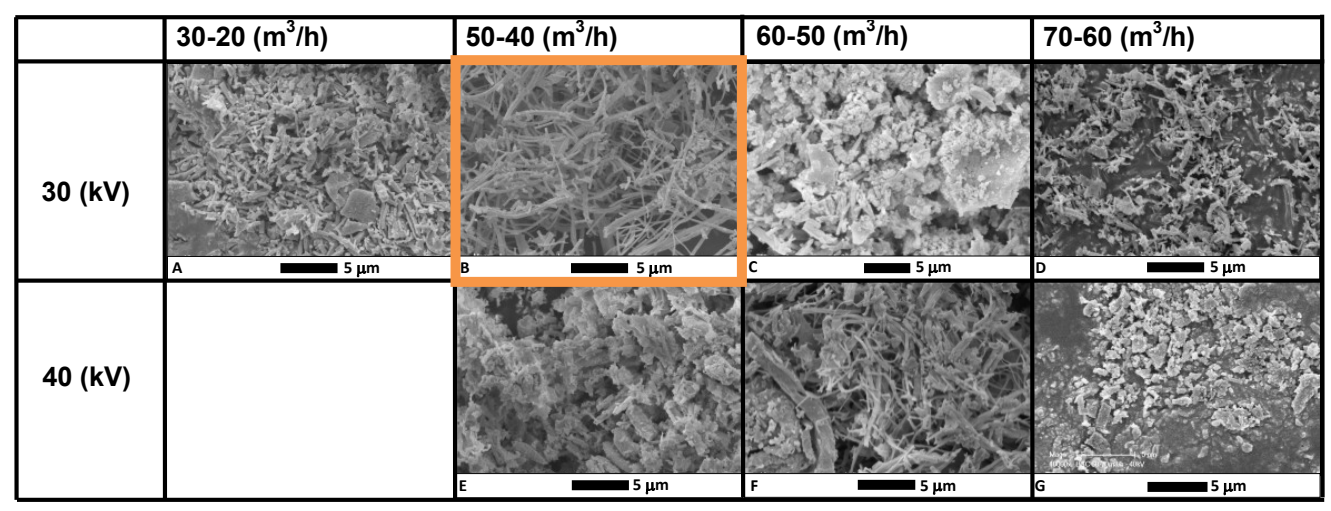

Figure 1. LaCe3 SEM micrographs of different samples (before calcination) obtained by diverse machine parameters: air flows and applied voltages. 


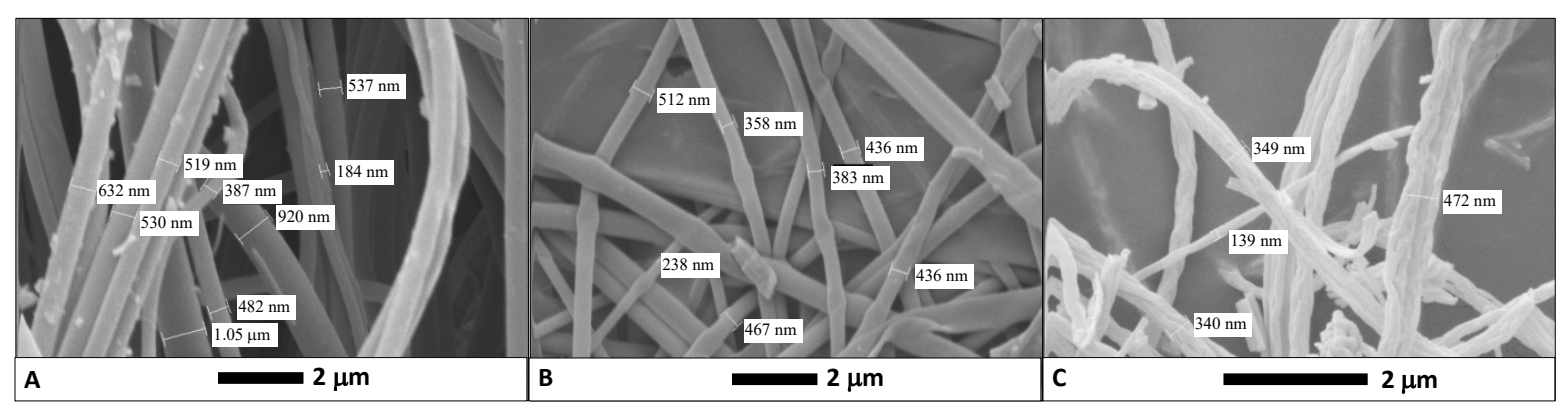

Figure 2. SEM micrographs of: (A) PVP nanofibers. (B) LaCe0.1@PVP nanofibers (before calcination) (C) $\mathrm{LaCe} 0.1$ nanofibers (after calcination at $625^{\circ} \mathrm{C}$ ). 


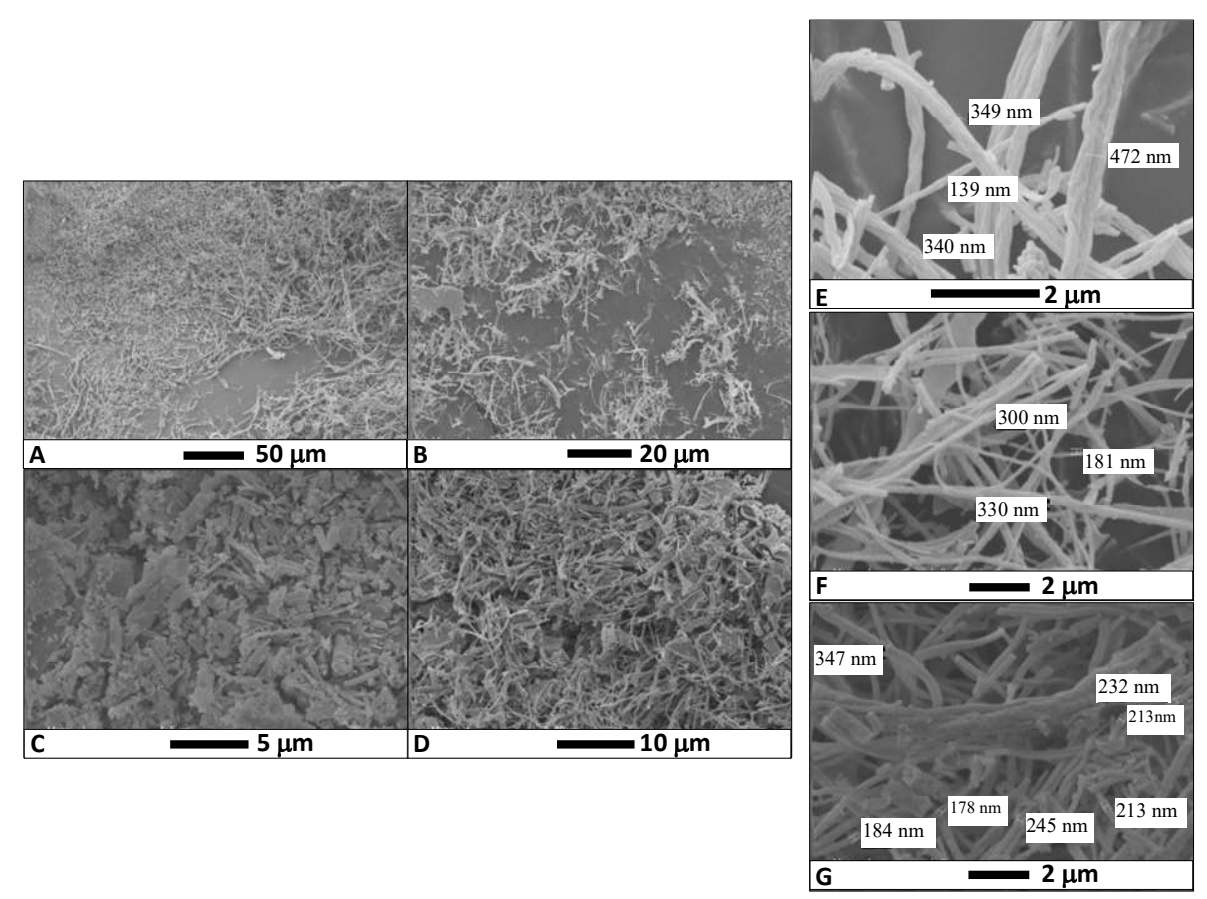

Figure 3. SEM micrographs of LaCe nanofibers (after calcination at $625^{\circ} \mathrm{C}$ ) with different compositions. (A) and (E) $\mathrm{LaCe} 0.1$, (B) and (F) $\mathrm{LaCe} 0.2$, (C) $\mathrm{LaCe} 1$, and (D) and (G) LaCe3. 


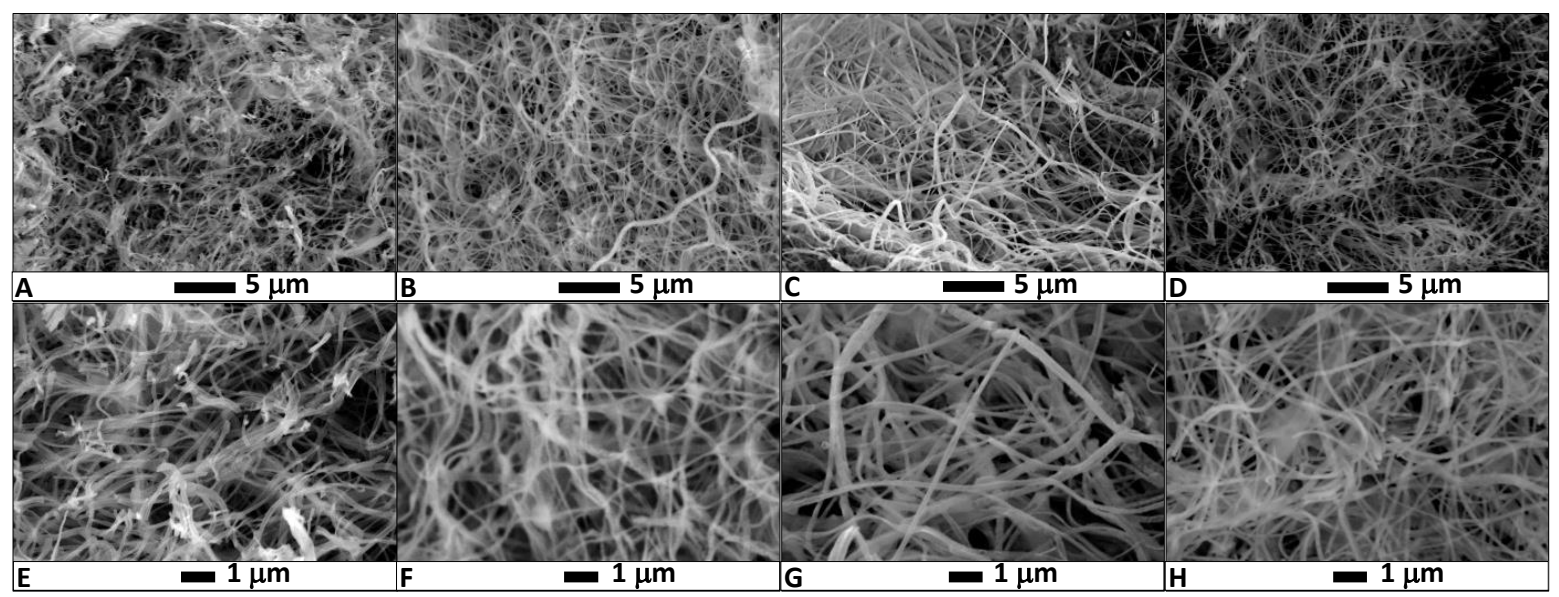

Figure 4. SEM micrographs of SrLaCe nanofibers (after calcination at $625{ }^{\circ} \mathrm{C}$ ) with different compositions. (A) and (E) SrLaCe0.1, (B) and (F) SrLaCe0.2, (C) and (G) SrLaCe1, and (D) and (H) SrLaCe3. 


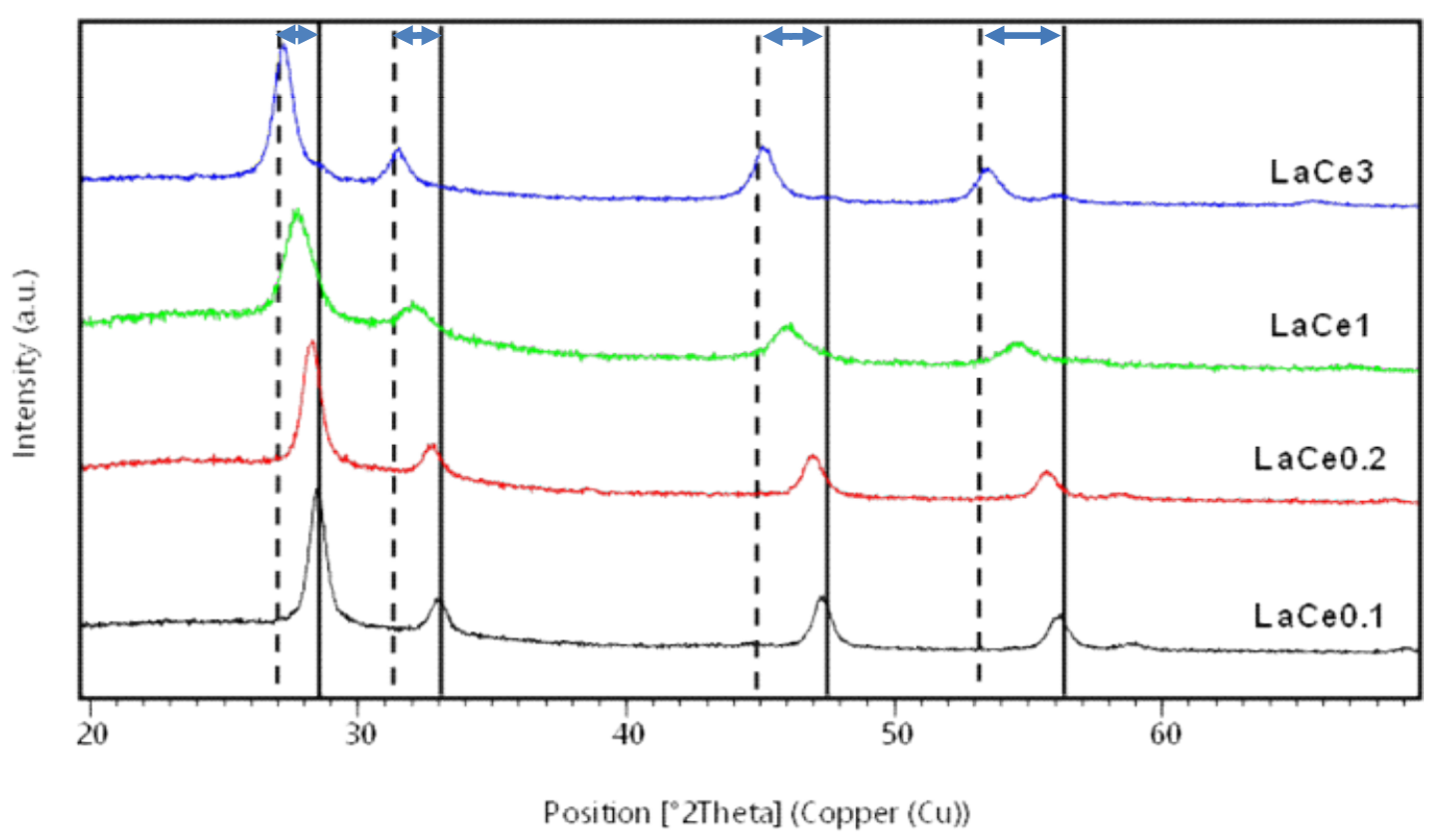

Figure 5. XRD patterns of $\mathrm{LaCe} 0.1, \mathrm{LaCe} 0.2, \mathrm{LaCe} 1$ and $\mathrm{LaCe} 3$ nanofibers: full lines indicate the XRD peak positions of cubic $\mathrm{CeO}_{2}$ (ICDD card 00-034-0394), dot lines those of $\mathrm{La}_{2} \mathrm{O}_{3}$ (ICDD card 03-065-3185) and $\leftrightarrow$ peak position possibilities of solid solutions $\mathrm{La}_{\mathrm{x}} \mathrm{Ce}_{\mathrm{y}} \mathrm{O}_{\mathrm{z}}$. 


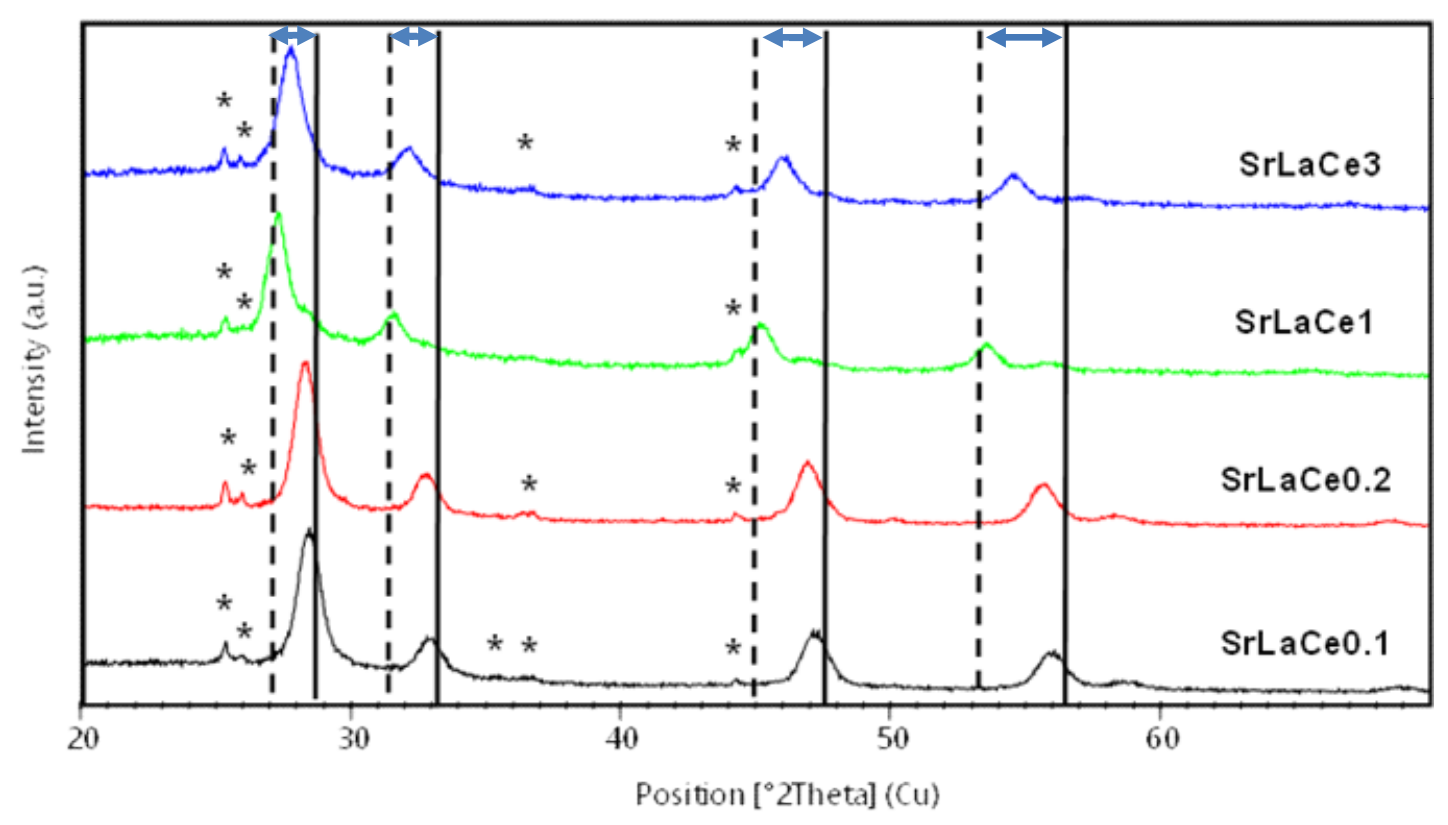

Figure 6. XRD patterns of $\mathrm{SrLaCe} 0.1, \mathrm{SrLaCe} 0.2, \mathrm{SrLaCe} 1$ and $\mathrm{SrLaCe} 3$ nanofibers: full lines indicate the XRD peak positions of cubic $\mathrm{CeO}_{2}$ (ICDD card 00-034-0394), dot lines those of $\mathrm{La}_{2} \mathrm{O}_{3}$ (ICDD card 03-065-3185), * those of $\mathrm{SrCO}_{3}$ and $\leftrightarrow$ peak position possibilities of solid solutions $\mathrm{La}_{\mathrm{x}} \mathrm{Ce}_{\mathrm{y}} \mathrm{O}_{\mathrm{z}}$. 

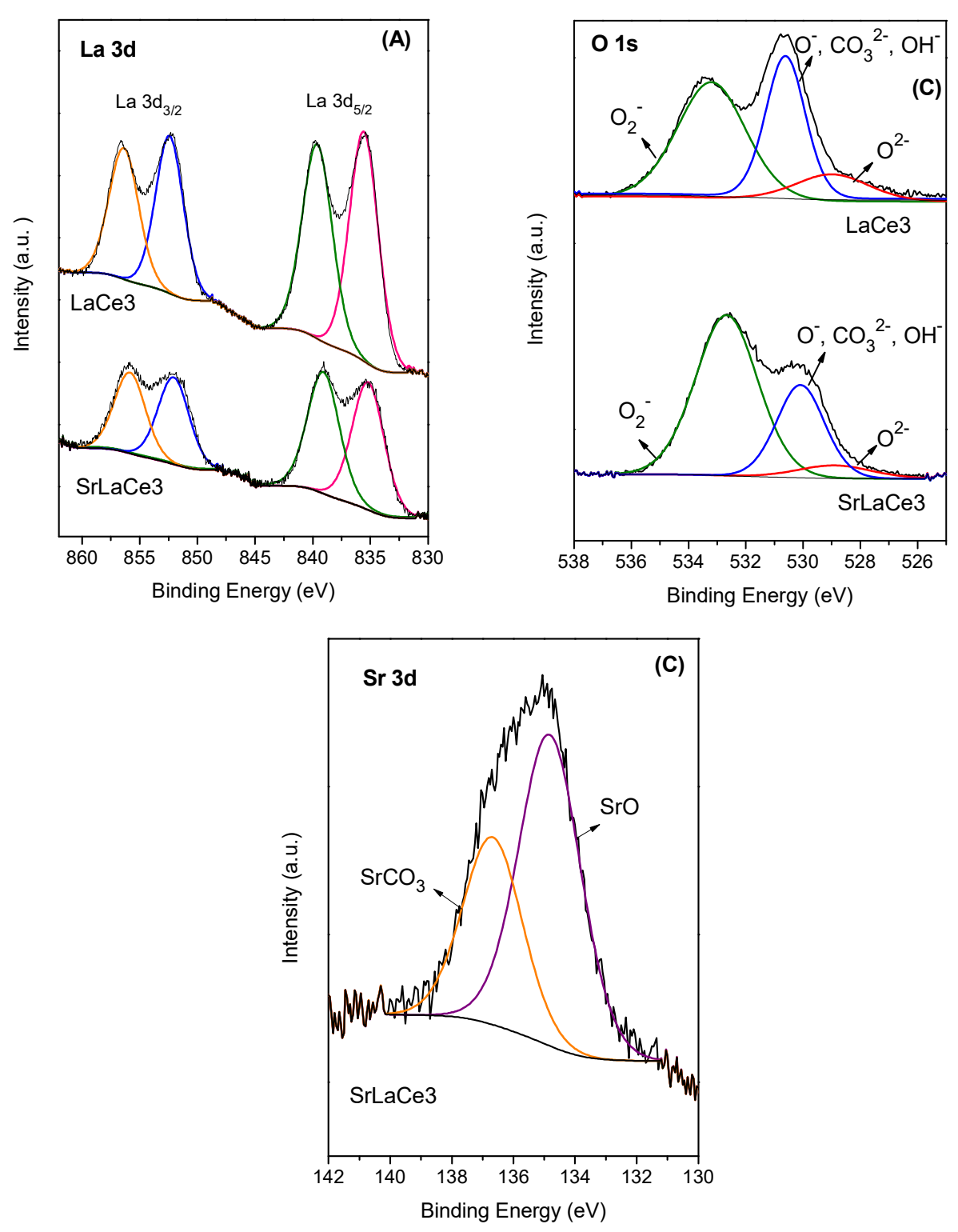

Figure 7. XPS results from SrLaCe3 and LaCe3 of: (A) La 3d, (B) O 1s and (C) Sr 3d regions. 

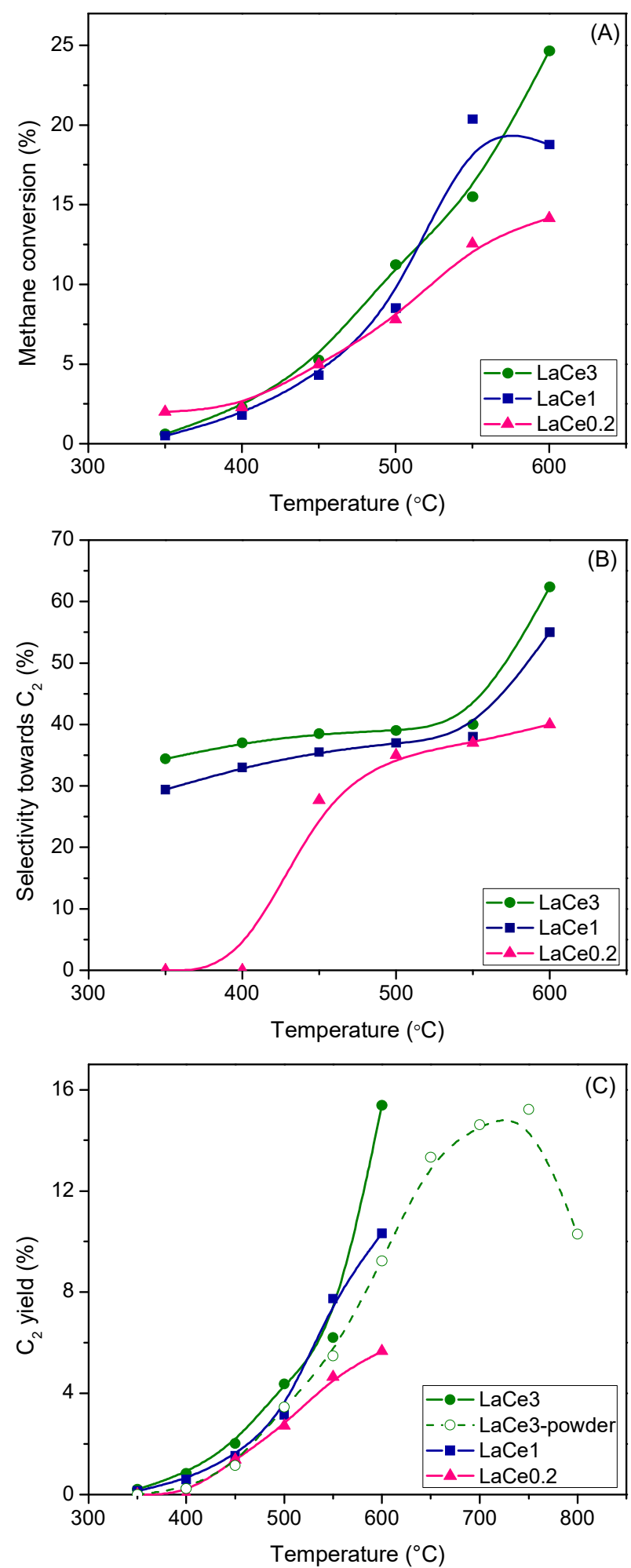

Figure 8. Catalytic behaviour of LaCe nanofibers: (A) Methane conversion, (B) selectivity towards $\mathrm{C} 2$ and (C) $\mathrm{C} 2$ yield. Reaction conditions: $\mathrm{W} / \mathrm{F}=0.166 \mathrm{mg} \mathrm{cm}^{-3} \mathrm{~h}$, Flow composition: 60 vol. $\% \mathrm{CH}_{4}, 12$ vol. $\% \mathrm{O}_{2}$ and $28 \%$ vol. He. 

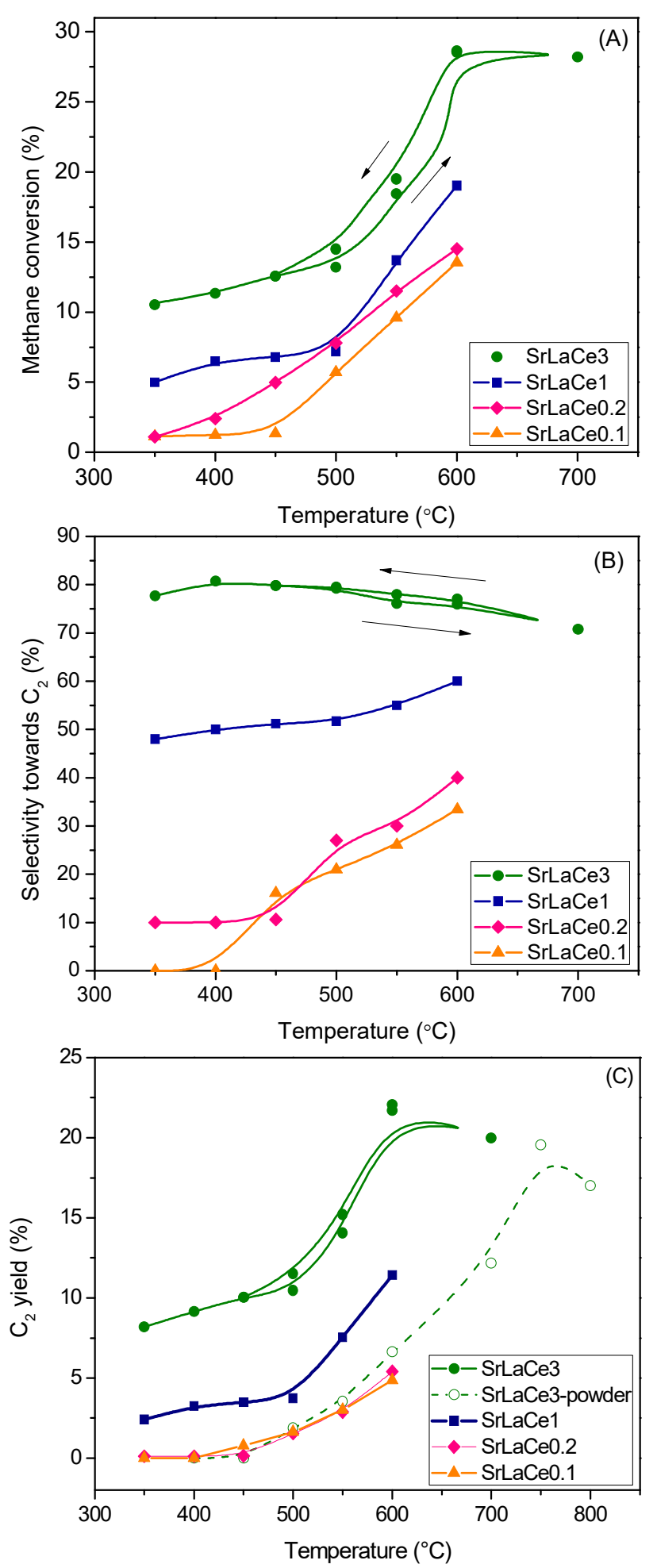

Figure 9. Catalytic behaviour of SrLaCe nanofibers: (A) Methane conversion, (B) selectivity towards $\mathrm{C}_{2}$ and $(\mathrm{C}) \mathrm{C}_{2}$ yield. Reaction conditions: W/F $=0.166 \mathrm{mg} \mathrm{cm}^{-3} \mathrm{~h}$, Flow composition: 60 vol. $\% \mathrm{CH}_{4}, 12$ vol. $\% \mathrm{O}_{2}$ and $28 \%$ vol. He. 
Table 1. Nomenclature of different nanofibers. Theoretical values of sample compositions and XRD identification.

\begin{tabular}{|c|c|c|c|c|c|c|}
\hline & $\begin{array}{c}\text { Ce } \\
\text { (wt. \%) }\end{array}$ & $\begin{array}{c}\text { La } \\
\text { (wt. \%) }\end{array}$ & $\begin{array}{c}\mathrm{Sr} \\
\text { (wt. \%) }\end{array}$ & $\mathrm{La} / \mathrm{Ce}$ & Identified phases & $\begin{array}{c}\text { ICDD } \\
\text { reference } \\
\text { cards }\end{array}$ \\
\hline LaCe0.1 & 90 & 10 & - & 0.11 & Near $\mathrm{CeO}_{2}$ & $\begin{array}{l}\text { Near 00- } \\
034-0394\end{array}$ \\
\hline LaCe0.2 & 80 & 20 & - & 0.25 & $\mathrm{La}_{0.2} \mathrm{Ce}_{0.8} \mathrm{O}_{1.9}$ & $04-016-6693$ \\
\hline LaCe1 & 50 & 50 & - & 1 & $\mathrm{La}_{0.5} \mathrm{Ce}_{0.5} \mathrm{O}_{2}$ & 04-006-3412 \\
\hline LaCe3 & 25 & 75 & - & 3 & $\begin{array}{c}\text { No card available but } \\
\text { near } \mathrm{La}_{2} \mathrm{O}_{3} \\
+\mathrm{CeO}_{2}\end{array}$ & $\begin{array}{c}\text { Near } \\
03-065-3185 \\
00-034-0394\end{array}$ \\
\hline SrLaCe0.1 & 85.7 & 9.3 & 5 & 0.11 & $\begin{array}{c}\mathrm{Sr}_{0.06} \mathrm{La}_{0.03} \mathrm{Ce}_{0.91} \mathrm{O}_{1.925} \\
\text { or } \mathrm{La}_{0.05} \mathrm{Ce}_{0.95} \mathrm{O}_{1.975} \\
\text { or } \mathrm{La}_{0.1} \mathrm{Ce}_{0.9} \mathrm{O}_{1.95} \\
\text { or } \mathrm{La}_{0.15} \mathrm{Ce}_{0.85} \mathrm{O}_{1.925} \\
+\mathrm{SrCO}_{3}\end{array}$ & $\begin{array}{l}04-021-0597 \\
01-080-3723 \\
01-080-3724 \\
04-019-5520 \\
01-084-1778\end{array}$ \\
\hline SrLaCe0.2 & 76.2 & 19 & 5 & 0.25 & $\begin{array}{l}\text { Same pattern than } \\
\qquad \mathrm{LaCe} 0.2 \\
\left(\mathrm{La}_{0.2} \mathrm{Ce}_{0.8} \mathrm{O}_{1.9}\right) \\
+\mathrm{SrCO}_{3}\end{array}$ & $\begin{array}{l}04-016-6693 \\
01-084-1778\end{array}$ \\
\hline SrLaCe1 & 47.6 & 47.6 & 5 & 1 & $\begin{array}{l}\text { Same phase than } \\
\qquad \mathrm{LaCe} 3 \\
+\mathrm{La}_{0.2} \mathrm{Ce}_{0.8} \mathrm{O}_{1.9} \\
+\mathrm{SrCO}_{3}\end{array}$ & $\begin{array}{c}\text { Near 03- } \\
065-3185 \\
04-016-6693 \\
01-084-1778\end{array}$ \\
\hline SrLaCe3 & 23.8 & 71.4 & 5 & 3 & $\begin{array}{l}\text { Same pattern than } \\
\qquad \mathrm{LaCe} 1 \\
\left(\mathrm{La}_{0.5} \mathrm{Ce}_{0.5} \mathrm{O}_{2}\right) \\
+\mathrm{SrCO}_{3}\end{array}$ & $\begin{array}{l}04-018-7404 \\
01-084-1778\end{array}$ \\
\hline
\end{tabular}


Table 2. Atomic concentration of SrLaCe nanofibers obtained by EDX technique.

\begin{tabular}{cccccc}
\hline Catalytic & \multicolumn{5}{c}{ Atomic concentration (\%) } \\
\cline { 2 - 6 } fibers & $\mathrm{Sr}$ & $\mathrm{La}$ & $\mathrm{Ce}$ & $\mathrm{O}$ & $\mathrm{C}$ \\
\hline SrLaCe0.1 & 4.7 & 1.9 & 16.0 & 57.2 & 20.2 \\
\hline SrLaCe0.2 & 4.7 & 4.9 & 18.6 & 48.2 & 23.6 \\
\hline SrLaCe1 & 4.5 & 8.7 & 8.0 & 60.4 & 18.4 \\
\hline SrLaCe3 & 4.6 & 18.5 & 5.8 & 47.9 & 23.2 \\
\hline
\end{tabular}


Table 3. XPS analysis results.

\begin{tabular}{|c|c|c|c|c|c|c|}
\hline \multirow{2}{*}{$\begin{array}{l}\text { Catalytic } \\
\text { fibers }\end{array}$} & \multicolumn{6}{|c|}{ Binding Energy $(\mathrm{eV})$} \\
\hline & La $3 d_{5 / 2}$ & La $3 d_{3 / 2}$ & Ce $3 d_{5 / 2}$ & Ce $3 d_{3 / 2}$ & O1s & Sr3d \\
\hline \multirow[t]{3}{*}{ LaCe3 } & 835.6 & 852.4 & 882.9 & 901.0 & $529.1 / 8.9^{a}$ & \\
\hline & $839.6^{\mathrm{b}}$ & $856.4^{\mathrm{b}}$ & 888.4 & 907.6 & $530.6 / 44.8$ & \\
\hline & & & 898.1 & 916.5 & $533.2 / 46.3$ & \\
\hline \multirow[t]{3}{*}{ SrLaCe3 } & 835.3 & 852.1 & 882.5 & 901.0 & $528.9 / 14.7$ & $134.8 / 63.6^{\mathrm{a}}$ \\
\hline & $839.1^{\mathrm{b}}$ & $855.9^{b}$ & 888.8 & 907.1 & $530.1 / 21.0$ & $136.6 / 36.4$ \\
\hline & & & 898.5 & 916.5 & $532.8 / 64.3$ & \\
\hline
\end{tabular}


Table 4. Concentration of constituent elements on the nanofibers surface.

\begin{tabular}{cccccc}
\hline \multirow{2}{*}{ Fibers } & \multicolumn{3}{c}{ Surface atomic concentration (\%) from XPS } & \multirow{2}{*}{ La/Ce } \\
\cline { 2 - 4 } & $\mathrm{Sr}$ & $\mathrm{La}$ & $\mathrm{Ce}$ & $\mathrm{O}$ & \\
\hline $\mathrm{LaCe} 3$ & - & 21.6 & 4.7 & 73.4 & 4.6 \\
\hline SrLaCe3 & 3.6 & 14.9 & 3.5 & 78.0 & 4.2 \\
\hline
\end{tabular}




\section{Abstract Graphics}

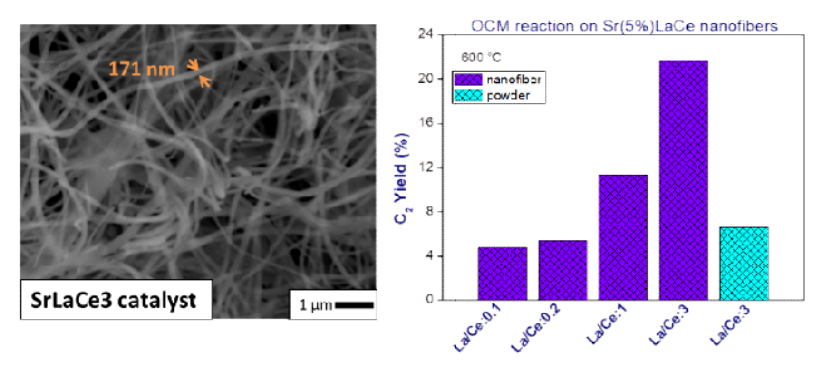

